\title{
Curdlan sulfate- $\mathrm{O}$-linked quaternized chitosan nanoparticles: potential adjuvants to improve the immunogenicity of exogenous antigens via intranasal vaccination
}

This article was published in the following Dove Press journal:

International Journal of Nanomedicine

\author{
Shu Zhang' \\ Shengshi Huang ${ }^{2}$ \\ Lu Lu' \\ Xinlei Song' \\ Pingli $\mathrm{Li}^{3}$ \\ Fengshan Wangl,2
}

'Key Laboratory of Chemical Biology of Natural Products (Ministry of Education), Institute of Biochemical and Biotechnological Drugs, School of Pharmaceutical Sciences, Shandong University, Jinan, Shandong, ${ }^{2} \mathrm{National}$ Glycoengineering Research Center, Shandong Provincial Key Laboratory of Carbohydrate Chemistry and Glycobiology, Shandong University, Jinan, Shandong, ${ }^{3}$ Institute of Clinical Pharmacology, Qilu Hospital of Shandong University, Jinan, Shandong, China
Correspondence: Fengshan Wang Institute of Biochemical and Biotechnological Drugs, School of Pharmaceutical Sciences, Shandong University, 44 Wenhuaxi Road, Jinan, Shandong 2500I2, China

$\mathrm{Tel}+8653$ I 88382589

Fax +86 53। 88382548

Email fswang@sdu.edu.cn
Introduction: The development of ideal vaccine adjuvants for intranasal vaccination can provide convenience for many vaccinations. As an ideal intranasal vaccine adjuvant, it should have the properties of assisting soluble antigens to pass the mucosal barrier and potentiating both systemic and mucosal immunity via nasal administration.

Methods: By using the advantages of polysaccharides, which can promote both T-helper 1 and 2 responses, curdlan sulfate $(\mathrm{CS})-O$-(2-hydroxyl)propyl-3-trimethyl ammonium chitosan chloride $(O$-HTCC) nanoparticles were prepared by interacting CS with $O$-HTCC, and the adjuvancy of the nanoparticles was investigated.

Results: The results showed that the polysaccharide-based nanoparticles induced the proliferation and activation of antigen-presenting cells. High protein-loading efficiency was obtained by testing with the model antigen ovalbumin (Ova), and the Ova adsorbed onto the cationic $\mathrm{CS} / \mathrm{O}$ HTCC complexes was taken up easily by the epithelium. To evaluate the capacity of the Ova/CS/ $O$-HTCC nanoparticles for immune enhancement in vivo, we collected and analyzed immunocytes, serum, and mucosal lavage fluid from intranasally vaccinated mice. The results showed that $\mathrm{Ova} / \mathrm{CS} / O$-HTCC nanoparticles induced activation and maturation of antigen-presenting cells and provoked the proliferation and differentiation of lymphocytes more significantly compared to the immunization of Ova mixed with aluminum hydroxide gel. Furthermore, CS/O-HTCC evoked a significantly higher level of Ova-specific antibodies.

Conclusion: Therefore, these results suggest that $\mathrm{CS} / O$-HTCC nanoparticles are ideal vaccine adjuvants for soluble antigens used in intranasal or mucosal vaccination.

Keywords: curdlan sulfate, $O$-linked quaternized chitosan, nasal mucosa immunization, nanoparticle, adjuvant, ovalbumin, immune response

\section{Introduction}

As the preferred choice to prevent various kinds of infectious diseases, such as influenza, hepatitis B, and tuberculosis, vaccination plays an indispensable role in controlling the dissemination of viruses or bacteria and reducing morbidity and mortality. Although traditional immunization methods (intramuscular and subcutaneous) can induce systemic immunoresponses, these methods are insufficient to evoke strong local immunity, particularly to elicit specific antibody responses in the mucosal region, which is the first barrier of defense against microorganisms. ${ }^{1}$

The nasal cavity has been proven to be a promising and attractive choice for mucosal immunization. As the first line of defense against inhaled viruses, nasopharynx-associated 
lymphoid tissue can mount strong mucosal immunoresponses. ${ }^{2,3}$ If antigens are inhaled and adsorbed on the surface of nasal mucosa, active antigen-presenting cells (APCs) under epithelial cells will recognize, phagocytize, and present them to lymphocytes to induce their differentiation, proliferation, and activation. ${ }^{4}$ However, soluble and nonadherent antigens can not only be blocked by the tight mucus and epithelial cells but also have low immunogenicity. ${ }^{5}$ FluMist Quadrivalent, the only type of intranasal vaccine approved against influenza, was reported by NBC News to show low treatment effectiveness (46\%-58\% efficiency during the 2015-2016 season), as well as various side effects.

Nanosized biomaterials, such as nanoparticles, nanoemulsions, liposomes, and nanogels, of pathogen-like size can provide a platform for soluble antigens to sustain long-lasting release. Antigens carried by nanosized biomaterials can be easily recognized by APCs, thus inducing more effective immunoresponse. ${ }^{6,7}$ Therefore, an effective vaccine formulation or delivery system would enhance the stability, adhesive capacity, and immunogenicity of antigens, providing strong mucosal and systemic immunity. As such, the development of a new generation of nasal mucosal vaccination strategies is necessary. ${ }^{8-11}$

Curdlan, an extracellular polysaccharide with a simple linear $\beta$-1,3-glucan structure, specifically recognizes the dectin 1 receptor on the surfaces of various immune cells. ${ }^{12}$ Recent research has shown that curdlan can activate dendritic cells through dectin 1 and TLR4. ${ }^{13}$ Compared to aluminum adjuvant, curdlan sulfate (CS), a soluble derivative of curdlan, shows satisfactory immunoenhancement activity in vitro ${ }^{14}$ and the ability to elicit stronger cellular and humoral responses in immunized mice. ${ }^{15} \mathrm{CS}$ also displays an antipathogen capacity in vitro and in vivo. ${ }^{16,17}$ Therefore, $\mathrm{CS}$ is a satisfying candidate for an immunoadjuvant. However, the negatively charged polysaccharide is hardly adsorbed by epithelia, which limit the applications of CS in mucosal immunotherapy.

Chitosan is the only alkaline polysaccharide found in nature and has been used as a mucosal absorption promoter for many years. ${ }^{18,19}$ Trimethylated chitosan as a drug carrier can assist many types of protein drugs across the mucosal barrier. ${ }^{18,20-25} \mathrm{O}$-(2-Hydroxyl)propyl-3-trimethyl ammonium chitosan chloride $(O$-HTCC) is a novel quaternized chitosan that facilitates the delivery of proteins or peptides. ${ }^{26,27}$ Sun and $\mathrm{Wan}^{28}$ reported that $O$-HTCC could form nanoparticles with sodium tripolyphosphate by an ionic gelation method. The nanoparticles showed high loading efficiency and loading capacity for bovine serum albumin.

In this study, cationic $O$-HTCC was chosen to carry and internalize the model antigen ovalbumin (Ova). CS as an immunologic stimulant and cross-linking agent interacted with $O$-HTCC to form CS/O-HTCC nanoparticles. The Ova-loaded nanoparticles (called Ova/CS/O-HTCC) were characterized by several methods to evaluate size, charge, Ova-loading efficiency, and cellular uptake. The potential of CS/

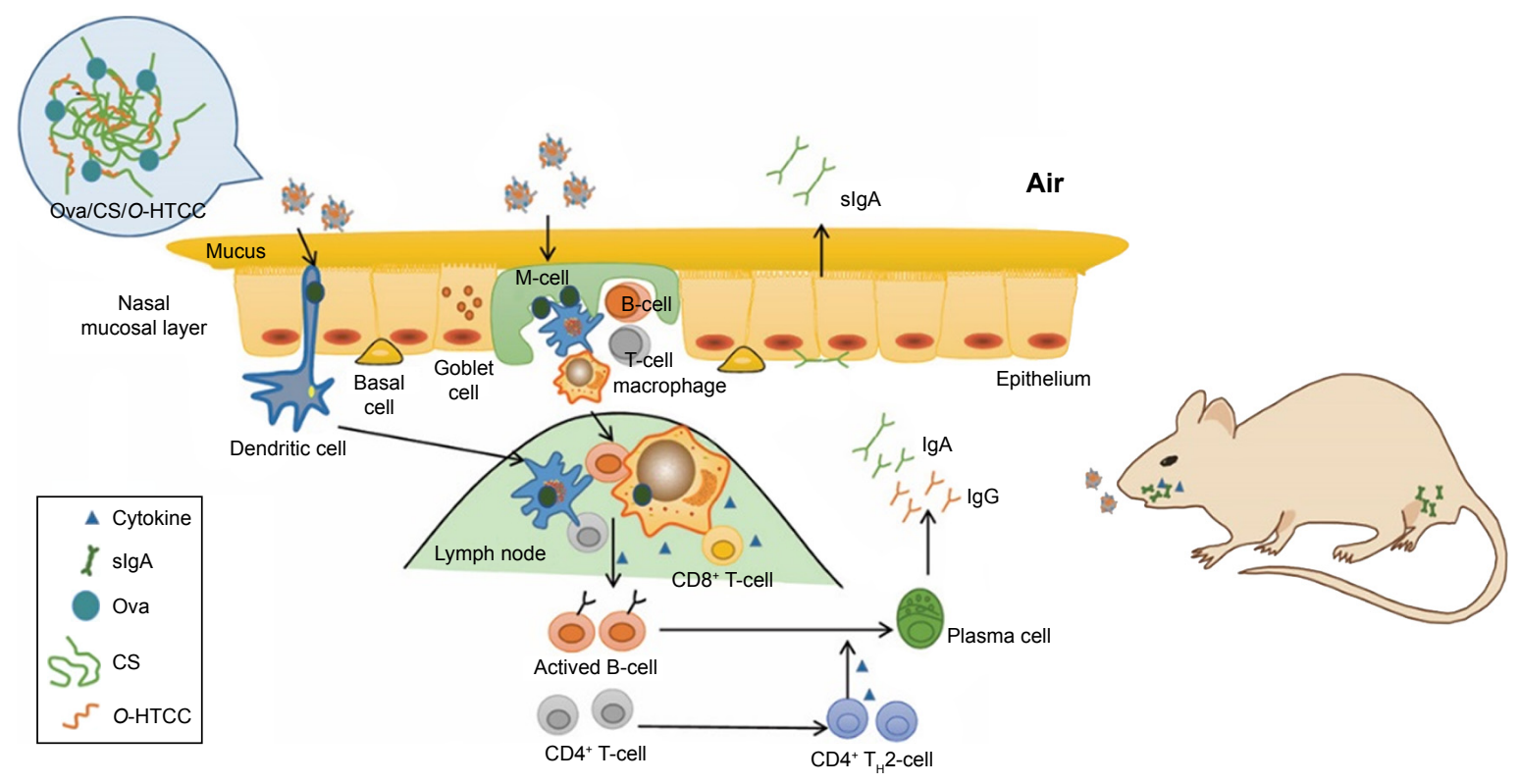

Scheme I CS/O-HTCC nanoparticles as a potential mucosal vaccine adjuvant.

Notes: Cationic CS/O-HTCC nanoparticles carry Ova to penetrate the nasal mucosal layer and facilitate the activation and proliferation of APCs. Then, the activated APCs trigger the secretion of cytokines and present the processed antigens to lymphocytes, which induce the proliferation and differentiation of these cells to evoke a high level of Ova-specific antibodies. Upon intranasal administration, the CS/O-HTCC nanoparticles boost a high expression level of secretory lgA (slgA) in both saliva and the vagina to induce mucosal immunoresponses.

Abbreviations: CS, curdlan sulfate; $\mathrm{O}-\mathrm{HTCC}, \mathrm{O}$-(2-hydroxyl)propyl-3-trimethyl ammonium chitosan chloride; Ova, ovalbumin; APCs, antigen-presenting cells; $\mathrm{T}_{\mathrm{H}} 2$, T-helper 2. 
$O$-HTCC as a nasal mucosal immunoadjuvant was evaluated with BALB/c mice (Scheme 1) by analyzing the activation and maturation of APCs, detecting the proliferation and differentiation of lymphocytes, and evaluating the expressions of antigen-specific antibodies in serum and mucosal lavage fluid after intranasal immunization.

\section{Materials and methods}

This work was performed in the Institute of Biochemical and Biotechnological Drugs and the Department of Pharmacology, School of Pharmaceutical Sciences, Shandong University.

\section{Materials}

Chitosan (molecular weight [MW] $100 \mathrm{kDa},>90 \%$ degree of deacetylation) was obtained from Haidebei Marine Bioengineering (Jinan, China). Curdlan (MW 100 kDa) was supplied by Zhongke Biotechnology (Weifang, China). Ova, glycidyl trimethylammonium chloride (GTMAC), and a sulfur trioxide-pyridine complex were purchased from Sigma-Aldrich (St Louis, MO, USA). Alhydrogel adjuvant 2\% (aluminum hydroxide gel) was obtained from InvivoGen (San Diego, CA, USA). MTT and fluorescein isothiocyanate (FITC) were obtained from Solarbio Bioscience and Technology (Shanghai, China). Neutral red was supplied by Sangon (Shanghai, China). Goat antimouse HRP-conjugated IgG, $\mathrm{IgG}_{1}, \mathrm{IgG}_{2 \mathrm{a}}$, and $\mathrm{Ig}$ A were purchased from Abcam (Cambridge, UK). IFN $\gamma$ and IL4 enzyme-linked immunosorbent assay (ELISA) kits were supplied by Bio-Swamp (Wuhan, China). Antimouse FITC-CD3, APC-CD4, FITC-CD4, PE-CD8a, PE-CD69, PE-F4/80, PE-CD11c, FITC-CD40, FITC-CD86, and FITC-major histocompatibility complex (MHC)-II were purchased from Thermo Fisher Scientific (Waltham, MA, USA). All other chemicals used were of analytical grade.

\section{Preparation of CS}

CS was prepared from curdlan as previously described by Li et al, ${ }^{14}$ with a slight modification. Briefly, $4 \mathrm{~g}$ curdlan was dissolved in $400 \mathrm{~mL}$ dried dimethyl sulfoxide by magnetic stirring overnight at room temperature. After curdlan had been completely dissolved, the temperature of the solution was adjusted to $65^{\circ} \mathrm{C}$, and $10 \mathrm{~g}$ sulfur trioxide-pyridine complex was added to the solution and mixed for 1 hour. Then, the reaction solution was cooled below $30^{\circ} \mathrm{C}$ in ice water bath. Methanol ( $2 \mathrm{~L})$ with $5 \%$ sodium acetate was added, and the reaction rested at room temperature for 4 hours to precipitate the product. After filtration, the precipitate was washed twice using methanol and dissolved in water. Then, the solution was desalted using ultrafiltration through a membrane with an MW cutoff of $5 \mathrm{kDa}$ and dried in a vacuum-freezing dryer to obtain CS. The structure of CS was confirmed by Fourier transform infrared (FT-IR) spectroscopy. The sulfur contents of CS were analyzed using an Elementar Vario EL III analyzer.

\section{Preparation of O-HTCC}

$O$-HTCC was synthesized according to a previously established method, ${ }^{25,26}$ with some modification. Chitosan $(9 \mathrm{~g}$, MW $100 \mathrm{kDa}$ ) was dissolved in $300 \mathrm{~mL} \mathrm{10 \%} \mathrm{(v:v)} \mathrm{acetic}$ acid aqueous solution at $40^{\circ} \mathrm{C}$. After chitosan had completely swelled, $47.4 \mathrm{~g}$ of benzaldehyde was added dropwise, and the solution stirred for 1 hour until a uniform milky colloid formed. After removing part of the solvent at $60^{\circ} \mathrm{C}$ (in a vacuum) overnight, the $\mathrm{pH}$ of the reaction product was adjusted to 7 with $1 \mathrm{M} \mathrm{NaOH}$. To obtain $N$-benzal chitosan, the precipitate was filtrated, washed twice with methanol, and dried overnight. Then, the precipitate was dissolved in $150 \mathrm{~mL}$ isopropyl alcohol by stirring at $70^{\circ} \mathrm{C}$. After that, $27 \mathrm{~g}$ GTMAC was added dropwise into the solution. The reaction was run for 16 hours, followed by filtration. The precipitate was washed, dried, and added to $150 \mathrm{~mL} 0.25 \mathrm{~mol} / \mathrm{L} \mathrm{HCl} \mathrm{eth-}$ anol solution with stirring at room temperature for 24 hours. After most of the ethanol had been removed using a rotary evaporator, $500 \mathrm{~mL}$ methanol was mixed into the solution and the solution rested overnight to precipitate the product. The product was washed and dissolved in water. To remove impurities and concentrate, an ultrafiltration system equipped with a membrane with an MW cutoff of $5 \mathrm{kDa}$ was used. Then, lyophilization was performed to obtain $O$-HTCC.

The reaction process was monitored by FT-IR spectroscopy. ${ }^{1} \mathrm{H}$ nuclear magnetic resonance (NMR) spectroscopy was used to confirm the identity of the final product. The degree of quaternization was calculated: ${ }^{28}$

$$
\frac{\left[\left(\mathrm{CH}_{3}\right)_{3}\right]}{[\mathrm{H}] \times 1 / 9} \times 100
$$

where $\left(\mathrm{CH}_{3}\right)_{3}$ is the peak area of the methyl protons of the trimethylammonium group and $\mathrm{H}$ is the peak area of the proton of the anomeric $-\mathrm{CH}$.

\section{Preparation and characterization of CS/O-HTCC and Ova/CS/O-HTCC nanoparticles}

$\mathrm{CS} / O$-HTCC and Ova/CS/O-HTCC nanoparticles were prepared by charge interactions using an ionic gelation method. CS (1 mg) was dissolved in $10 \mathrm{~mL}$ water to serve as the physical cross-linker and immunopotentiator. Under 
continuous stirring, $500 \mu \mathrm{L} 0.5 \mathrm{mg} / \mathrm{mL} O$-HTCC was added dropwise to $500 \mu \mathrm{L} 0.1 \mathrm{mg} / \mathrm{mL}$ CS solution to obtain the $\mathrm{CS} / O$-HTCC nanoparticles. To form Ova/CS/O-HTCC nanoparticles, $500 \mu \mathrm{L} 0.4 \mathrm{mg} / \mathrm{mL}$ Ova dissolved in doubledistilled water was added dropwise to the $\mathrm{CS} / O$-HTCC nanosolution under continuous stirring.

Particle size and $\zeta$-potential were measured by laser Doppler velocimetry using a Zetasizer Nano ZS (Malvern Instruments, Malvern, UK). To characterize the morphology, nanoparticles were visualized with transmission electron microscopy. After centrifugation $(20,000 \times g, 10$ minutes $)$, supernatants were collected to analyze loading efficiency. Sediments were resuspended in $1 \mathrm{~mL} 0.01 \mathrm{M}$ PBS ( $\mathrm{pH} 7.4$ ) and incubated at $37^{\circ} \mathrm{C}$. At $0,0.5,1,2,4,12,24$, and 48 hours, $100 \mu \mathrm{L}$ solution was taken and centrifuged $(20,000 \times g$, 10 minutes). Loading efficiency and in vitro release of the Ova-loaded nanoparticles were determined by sodium dodecyl sulfate polyacrylamide gel electrophoresis. Loading efficiency was calculated:

$$
\frac{\text { Total protein }- \text { Free protein }}{\text { Total protein }} \times 100
$$

and the ratio of release calculated:

Free protein

$\overline{\text { Total protein } \times \text { Loading efficiency }}$

\section{Assessment of antigen uptake in vitro}

Ova and FITC were dissolved in sodium carbonate buffer ( $\mathrm{pH} 9.5)$. FITC (1 mL, $1 \mathrm{mg} / \mathrm{mL})$ was added dropwise to $1 \mathrm{~mL}$ Ova $(10 \mathrm{mg} / \mathrm{mL})$ aqueous solution under continuous stirring at $4^{\circ} \mathrm{C}$ in the dark. The reaction was run overnight, followed by termination with $0.007 \mathrm{~g}_{\text {of }} \mathrm{NH}_{4} \mathrm{Cl}$. The product was finally purified by dialysis using dialysis tubing with an $\mathrm{MW}$ cutoff of $1 \mathrm{kDa}$ at $4^{\circ} \mathrm{C}$ in the dark and lyophilized for 48 hours.

FITC-Ova/O-HTCC and FITC-Ova/CS/O-HTCC nanoparticles were prepared using the same method as the Ovaloaded nanoparticles. Then, Calu3 cells (purchased from Suer Biological Technology, Shanghai, China) were seeded in a 96-well plate with $2 \times 10^{4}$ cells per well. FITC-Ova and FITCOva-loaded nanoparticles were added to each well and incubated for 2 hours to allow FITC-labeled protein to be taken up by the Calu3 cells. Uptake efficiency was observed using fluorescence microscopy. Fluorescence-intensity percentage was measured using flow cytometry. Individual fluorescence of 10,000 cells was collected for each group.
In vitro internalization of FITC-Ova-loaded complexes in APCs was also analyzed. First, resident peritoneal macrophages were obtained using a previously described method. ${ }^{29}$ After disinfection, peritoneal cells of the mice were harvested by lavage of the peritoneum with $5 \mathrm{~mL}$ Hank's balanced salt solution. DC2.4 cell lines (maintained in our lab) and peritoneal macrophages were seeded in six-well plates. After incubation with the FITC-Ova and FITC-Ova-loaded complexes for 2 hours, internalization was measured using fluorescence microscopy.

\section{Intranasal immunization and sample collection}

Female BALB/c mice (6-8 weeks old, purchased from Vital River Laboratory Animal Technology, Beijing, China) were housed with free access to rodent chow and water at room temperature for 1 week before the study. The mice were randomly divided into seven groups, and each group comprised 10 mice. Animal experiments were approved by the Experimental Animal Welfare and Ethics Committee of Shandong University and performed following ethical guidelines for the care and use of animals. All mice were intranasally immunized on days 1, 15, and 29 with various formulations (Table S1). As shown in Table S1, on days 14, 28, and 42, retro-orbital blood samples were collected and then rested for 2 hours at room temperature. The serum was separated by centrifugation and stored at $-80^{\circ} \mathrm{C}$ for analysis. At 2 weeks after the final immunization, samples (ie, saliva, vaginal fluid, and spleens) were collected for further assays.

\section{Splenocyte proliferation assay}

Splenocytes of mice in each group were prepared using a previously reported method ${ }^{14}$ and seeded on the 96-well plates with $2 \times 10^{6}$ cells/well. After culturing for 12 hours at $37^{\circ} \mathrm{C}$, cells were treated with $10 \mu \mathrm{g} / \mathrm{mL}$ Ova to stimulate for 48 hours. The rate of proliferation was measured using the MTT method.

\section{Lymphocyte transformation assay}

Lymphocytes of mice were obtained and cultured as previously described. Lipopolysaccharide and concanavalin A were used to stimulate the transformation of the lymphocytes. After treatment for 48 hours, the ratio of proliferation was detected by MTT assay.

\section{Flow cytometry analysis of surface markers on immunocytes}

Spleen leukocytes of mice in each group were obtained and stained with fluorescence-labeled antibodies (against CD3, 
CD4, CD8, CD69, F4/80, CD11c, CD40, CD86, and MHCII) for 1 hour at $4{ }^{\circ} \mathrm{C}$ in the dark. The cells were washed three times using PBS to remove free antibodies and processed into single-cell suspensions. The expression of surface markers was analyzed by flow cytometry.

\section{Peritoneal macrophage proliferation assay}

Resident peritoneal macrophages were obtained as previously mentioned and planted with $2 \times 10^{5}$ cells per well in 96-well plates. Cells were treated with $10 \mu \mathrm{g} / \mathrm{mL}$ Ova for 48 hours, and then their capacity for proliferation was measured by MTT assay.

\section{Neutral red internalization experiment}

Resident peritoneal macrophages were seeded in a 96-well plate with $2 \times 10^{5}$ cells per well and treated with $100 \mu \mathrm{L}$ Ova $(10 \mu \mathrm{g} / \mathrm{mL})$ for 48 hours. Then, $0.1 \%$ (w:v) neutral red dissolved in Hank's balanced salt solution was added to each well, and the wells incubated for 30 minutes at $37^{\circ} \mathrm{C}$. To remove excess dye, plates were washed three times using PBS at room temperature. Then, the supernatant was discarded and $100 \mu \mathrm{L}$ of lysis buffer ( $50 \%$ ethanol $/ 50 \%$ acetic acid) added to each well. After wells had stood for 3 hours, optical density at $540 \mathrm{~nm}$ was detected by a microplate reader.

\section{Determination of cytokines in mouse sera by ELISA}

To measure the expression of cytokines (IFN $\gamma$ and IL4), serum was analyzed with the ELISA kits. Optical density at $540 \mathrm{~nm}$ was measured by a microplate reader. Concentrations of these cytokines were calculated by comparing with the standard proteins.

\section{Determination of Ova-specific antibody levels in mouse sera}

Expression of Ova-specific $\operatorname{IgG}, \operatorname{IgG}_{1}, \operatorname{IgG}_{2 \mathrm{a}}$, and IgA antibodies were detected by an indirect ELISA method. Briefly, after coating with a $5 \mu \mathrm{g} / \mathrm{mL}$ Ova solution (in $50 \mathrm{mM}$ carbonate-bicarbonate buffer, $\mathrm{pH}$ 9.6) overnight, the 96-well plates were washed three times with PBS containing $0.05 \%$ Tween 20 by a microplate washer and then blocked with $200 \mu \mathrm{L} 1 \%$ bovine serum albumin at $37^{\circ} \mathrm{C}$ for 2 hours. The serum of the mice in each group was proportionally diluted and added to the washed wells. The plates were then incubated for 1 hour at $37^{\circ} \mathrm{C}$, followed by washing three times. Then, $100 \mu \mathrm{L}$ diluted HRP-conjugated antibody $(1: 1,000)$ was added to the wells and incubated to react with Ova for 1 hour at $37^{\circ} \mathrm{C}$. To determine the concentration of anti-Ova

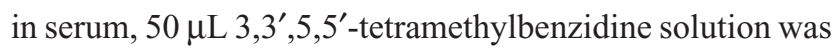
added to the washed wells to generate chromogenesis for 10 minutes at $37^{\circ} \mathrm{C}$. The reaction was terminated by adding $30 \mu \mathrm{L} /$ well $2 \mathrm{M} \mathrm{H}_{2} \mathrm{SO}_{4}$, followed by measuring optical density at $540 \mathrm{~nm}$.

\section{Determination of Ova-specific slgA production by ELISA}

To evaluate the mucosal immunoactivity of the Ova/CS/ $O$-HTCC nanoparticles, saliva and vaginal lavage fluid were obtained. After centrifugation (4,000 rpm, 10 minutes), the supernatant was collected and tenfold diluted. Generation of Ova-specific secretory $\operatorname{IgA}$ (sIgA) in these samples were measured by ELISA using the aforementioned method.

\section{Statistical analysis}

All quantitative data are expressed as mean \pm SD. Oneway analysis of variance was used to determine statistical significance among various groups using GraphPad Prism software.

\section{Results and discussion Preparation of CS and O-HTCC}

Carbohydrates, such as curdlan and chitosan, have been shown to possess immunological activities. However, their poor solubility limits their biomedical applications, especially as adjuvants. These carbohydrates must be dissolved below $\mathrm{pH}$ 6, while many kinds of antigens, such as inactivated influenza virus, are unstable in acidic $\mathrm{pH} .{ }^{30}$ To overcome this obstacle, chemical modifications (such as sulfation and quaternization) of polysaccharides with inactive groups have been shown to be a potent strategy. Therefore, in this study, $\mathrm{CS}$ and $\mathrm{O}$-HTCC were chosen to act as antigen delivery systems. First, a dimethyl sulfoxide-sulfur trioxide-pyridine system was used to modify curdlan with hydroxyl groups (Figure 1A). From the FT-IR spectra of curdlan and its sulfated derivative, as shown in Figure S1A, the characteristic peak at $1,225 \mathrm{~cm}^{-1}$ corresponding to asymmetrical $\mathrm{S}=\mathrm{O}$ stretching indicated the presence of sulfate groups. A symmetrical $\mathrm{C}-\mathrm{O}-\mathrm{S}$ stretching-induced absorption peak was also observed at $815 \mathrm{~cm}^{-1}$. In Table S2, elemental analysis results showed that the extent of sulfation of CS was $13.738 \%$. All the results confirmed that CS was successfully produced.

To improve the water solubility of chitosan, the quaternization reagent GTMAC was used to react selectively with the C-6-OH groups on 2-amino-protected chitosan (Figure 1B). Figure S1B shows the FT-IR results. In intermediate products 


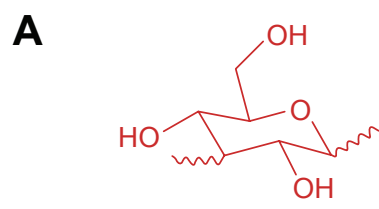

B a

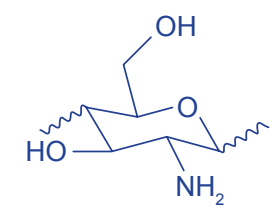

C

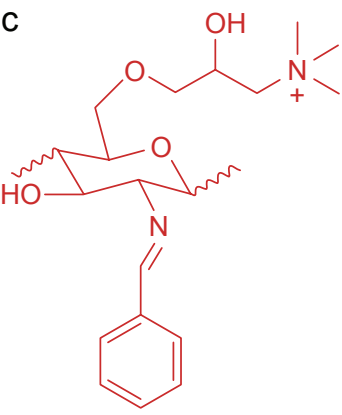

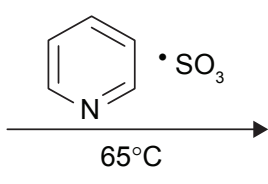

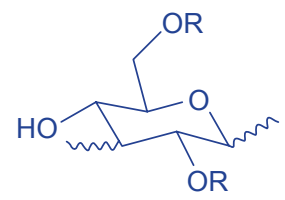

$\mathrm{R}=\mathrm{SO}_{3} \mathrm{Na}$ or $\mathrm{H}$
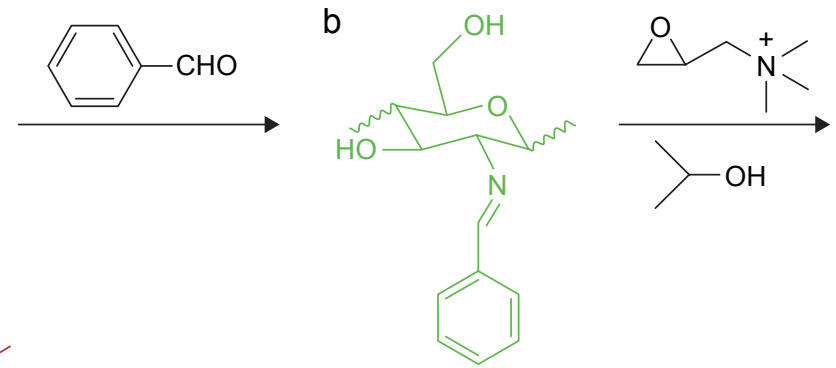

$\mathrm{HCl} / \mathrm{CH}_{3} \mathrm{CH}_{2} \mathrm{OH}$

d

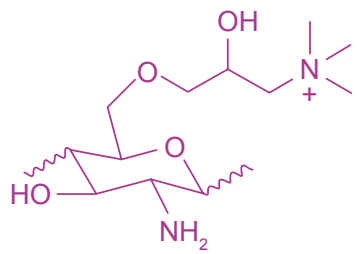

Figure I Preparation of CS and O-HTCC.

Notes: (A) Synthetic route of CS; (B) synthetic route of O-HTCC; a, chitosan; b, N-benzylidene chitosan; c, O-quaternary aminonium-N-benzylidene chitosan; and d, O-HTCC.

Abbreviations: CS, curdlan sulfate; O-HTCC, O-(2-hydroxyl)propyl-3-trimethyl ammonium chitosan chloride.

$\mathrm{b}$ and $\mathrm{c}$, the peaks at 690 and $760 \mathrm{~cm}^{-1}$ formed by substitution of the aromatic ring certified the grafting of benzaldehyde groups onto $\mathrm{C}-2-\mathrm{NH}_{2}$. However, the peaks vanished in product $\mathrm{d}$, which indicated deprotection by the hydrochloric acid-ethanol solution. The $\mathrm{C}-\mathrm{H}\left(\mathrm{eg},-\mathrm{CH}_{2}-,-\mathrm{CH}_{3}\right)$ bending vibrations induced a strong absorption peak at $1,480 \mathrm{~cm}^{-1}$ in products $\mathrm{c}$ and $\mathrm{d}$, which verified the existence of quaternary ammonium groups. From the ${ }^{1} \mathrm{H}$ NMR spectra of $O$-HTCC (Figure $\mathrm{S} 2$ ), the peak at $\delta=3.125 \mathrm{ppm}\left(-{ }^{+} \mathrm{N}\left[\mathrm{CH}_{3}\right]_{3}\right)$ also proved the successful synthesis of $O$-HTCC. The degree of quaternization was $30.22 \%$ according to the calculated formula. The modified polysaccharides $(\mathrm{O}$-HTCC and CS) improved the strength of the positive and negative charges, respectively, which increased the repulsion force between the functional groups to cause the complex to expand in water solution.

\section{Preparation of CS/O-HTCC and Ova/ CS/O-HTCC nanoparticles}

Preparation of the empty and Ova-loaded nanoparticles is depicted in Scheme 2. The empty nanoparticles were prepared with anionic CS and cationic $O$-HTCC by ionic gelation, a mild method avoiding the use of organic solvents or sonication. The order of reagent addition, mixing ratio, dropping speed, and stirring speed influenced the formation of nanoparticles. Compared with adding $\mathrm{CS}$ to the $O$-HTCC solution, adding $O$-HTCC to the CS solution resulted in more uniform nanoparticles. Upon evaluation of the size, size distribution, and $\zeta$-potential, we found that the size and $\zeta$-potential of the nanoparticles did not increase with increasing addition of $O$-HTCC. When the $O$-HTCC concentration was relatively low, the complexes formed were loose, exposing more positive charges. As shown in Figure 2, uniform and spherical CS/O-HTCC nanoparticles were formed when the $O$-HTCC solution was added dropwise into the CS solution at an $O$-HTCC:CS ratio of 5 (w:w) with slow mixing (300 revolutions/minute). Then, Ova/CS/O-HTCC nanoparticles were prepared using the same method. Analysis of unloaded and loaded nanoparticles indicated that both complexes had narrow size distribution, which agreed with the morphology observed by transmission electron microscopy. Table S3 displays the characteristics of the empty and Ova-loaded nanoparticles. The results show that nanoscale and uniform particles with positive $\zeta$-potential formed. Although negatively charged Ova interacted with positively charged 

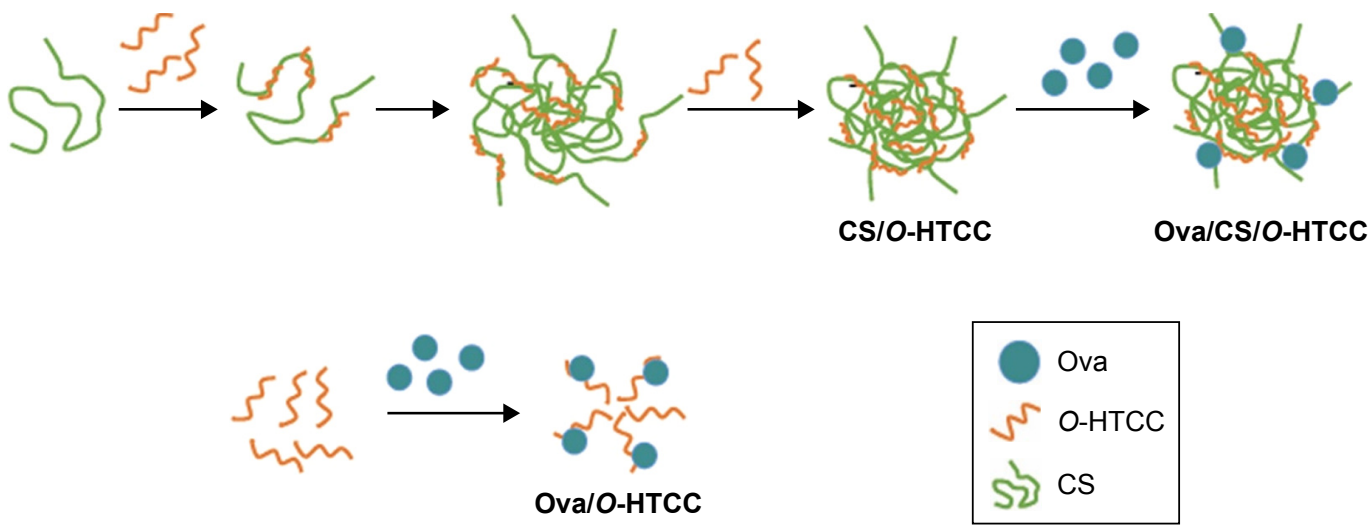

Scheme 2 Preparation of empty and Ova-loaded nanoparticles.

Abbreviations: Ova, ovalbumin; CS, curdlan sulfate; O-HTCC, O-(2-hydroxyl)propyl-3-trimethyl ammonium chitosan chloride.

$O$-HTCC to form a polyelectrolyte complex, this kind of complex exhibited considerably increased particle size and polydispersity-index values compared to $\mathrm{Ova} / \mathrm{CS} / O$-HTCC. These results indicate that $\mathrm{CS}$ with a high degree of substitution acted as a cross-linking agent to assemble the positively charged chitosan derivative tightly.
Generally, the amount of protein can be measured by bicinchoninic acid assay; however, we found that $O$-HTCC as an interfering substance affected the precision of the detection. Therefore, loading efficiency and release rate were measured by sodium dodecyl sulfate polyacrylamidegel electrophoresis and calculated by the band intensities.
A
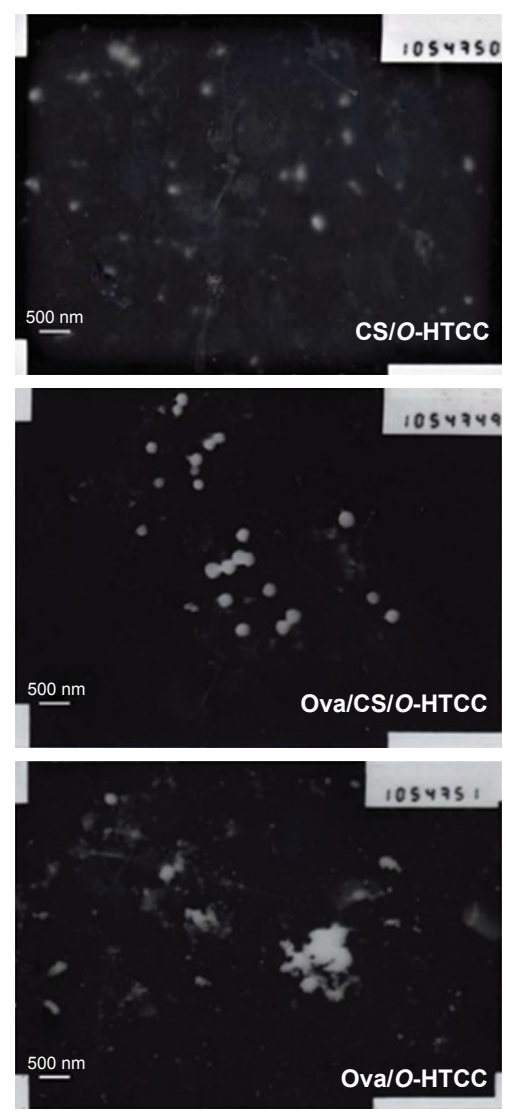

B
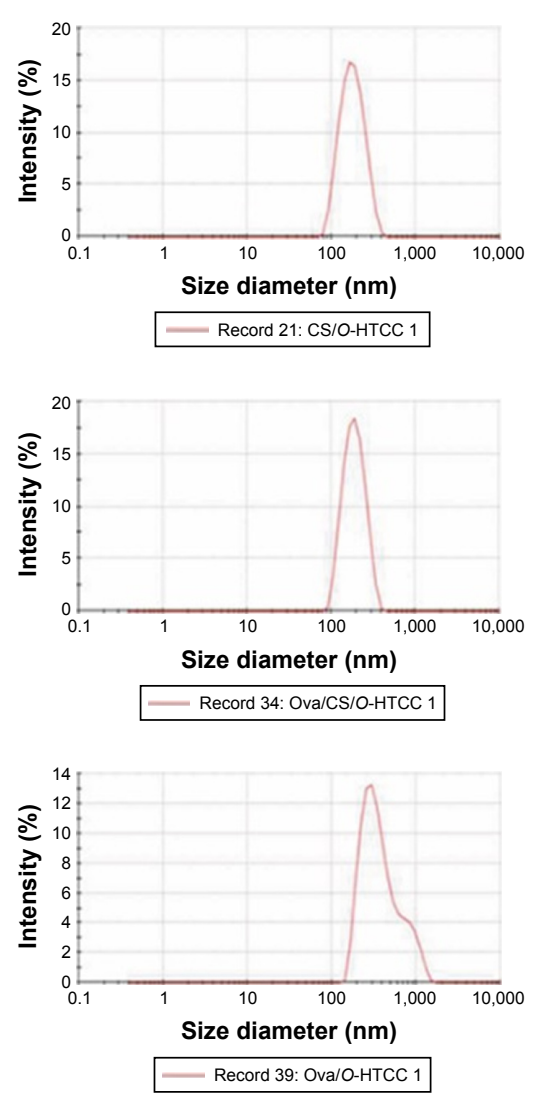

C
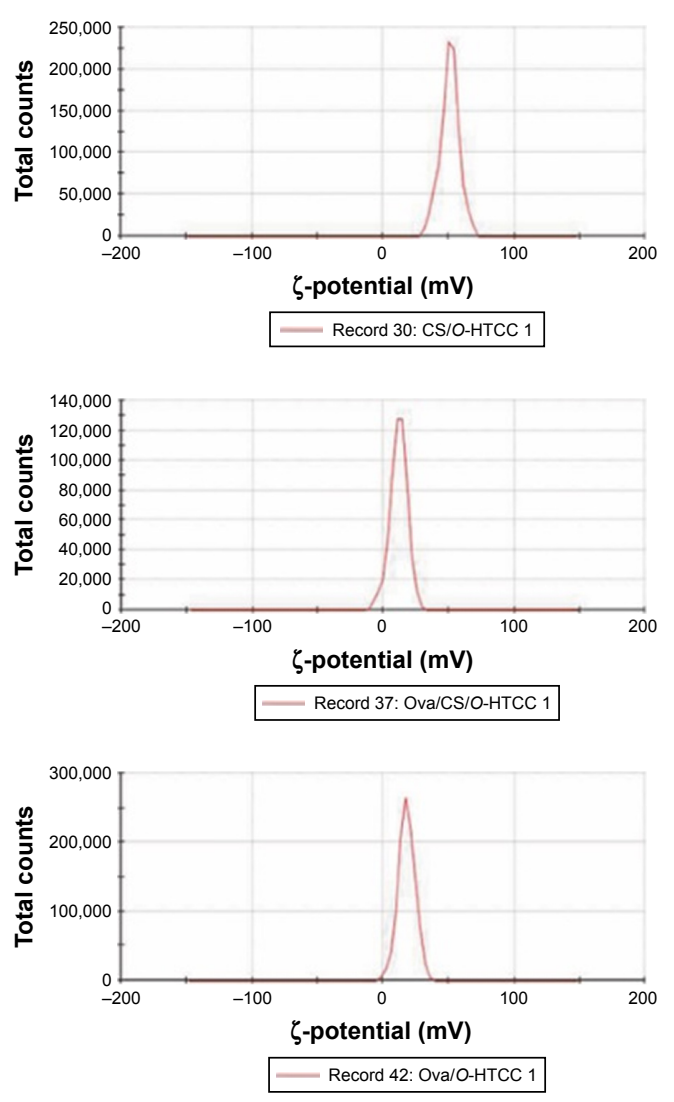

Figure 2 Physicochemical properties of the complexes.

Notes: (A) Transmission electron microscopy imaging of the complexes; (B) size distribution of the complexes; (C) $\zeta$-potential distribution of the complexes.

Abbreviations: CS, curdlan sulfate; O-HTCC, O-(2-hydroxyl)propyl-3-trimethyl ammonium chitosan chloride; Ova, ovalbumin. 
As shown in Figure S3, Ova was efficiently adsorbed on the $\mathrm{CS} / O$-HTCC nanoparticles (72.6\%). After standing for 48 hours, the percentage of free Ova in the Ova/CS/O-HTCC and Ova/O-HTCC solutions increased from $37.7 \%$ to $83.9 \%$ and from $45.4 \%$ to $87.2 \%$, respectively, which illustrated that the carriers provided sustained release of the protein without burst release (Figure 3). Furthermore, the sodium dodecyl sulfate polyacrylamide-gel electrophoresis results confirmed the structural integrity of Ova in the nanoparticles, which was the key to maintaining the immunoregulatory activity of the antigens.

\section{Effect of CS/O-HTCC on cellular uptake ability of epithelial cells}

Ingestion of antigens by nasal epithelial cells is the first step in nasal immunization. Many conventional antigen carriers may be hindered by dense mucus layers. ${ }^{31}$ For example, negatively charged poly(lactic-co-glycolic acid) nanoparticles are not suitable for mucosal delivery. Although some mucoadhesive carriers can adhere to the mucus, they hardly penetrate the mucus layer. ${ }^{32}$ Fluorescence microscopy confirmed that $O$-HTCC promoted the phagocytosis function of epithelium cells (Figure 4A), which was also confirmed by flow-cytometry analysis (Figure 4B and C). The CS/OHTCC complex solution showed high viscosity, which indicated that is has the potential application as a mucoadhesive agent. Since the negatively charged cell surfaces hardly adhered and internalized FITC-Ova, $O$-HTCC interacted with the epithelial cells and induced a redistribution of cytoskeletal F-actin. As such, compared with the other nanocarriers, $\mathrm{CS} / \mathrm{O}$-HTCC nanoparticles, which are based on quaternized chitosan, ${ }^{33}$ showed several advantages, including mucoadhesive capacity and permeation-enhancement properties. Based on the negative charge, CS stabilized the formation of nanoparticles and reduced the mucosal irritation induced by the cationic $O$-HTCC, while also neutralizing the cationic complex and slightly reducing uptake efficiency.

\section{Effect of CS/O-HTCC as a nasal immunization adjuvant on Ova-induced cellular immunoresponses}

Once pathogens enter cells, cellular immunity, a protective immune process that involves the internalization of antigens, proliferation, and activation of antigen-sensitized lymphocytes and the release of cytokines, plays a crucial role in fighting against pathogen-induced infection. To investigate the potential activity of $\mathrm{CS} / O$-HTCC as a nasal immunization adjuvant, we studied the effects of $\mathrm{CS} / O$-HTCC on cellular immunoresponse of mice immunized with Ova.

Stimulation of lymphocytes by specific or aspecific mitogens promotes the production of lymphokines, followed by proliferation and differentiation of various effector cells, such as $\mathrm{T}$ lymphocytes and B lymphocytes. The effect of the polysaccharides on Ova-stimulated lymphocyte proliferation in immunized mice is shown in Figure 5A. The proliferation of lymphocytes in the mice immunized with Ova/CS/O-HTCC was significantly higher than that in other groups $(P<0.001)$. Mouse nasal immunization with Ova/ $\mathrm{CS} / O$-HTCC also showed strong capacity for T-lymphocyte and B-cell transformation (Figure 5B and C). Analysis of the T-lymphocyte subtypes in Figure 5D-H indicated that $\mathrm{CS}$ and $O$-HTCC could amplify Ova-induced recruitment of $\mathrm{T}$-helper $\left(\mathrm{T}_{\mathrm{H}}\right)$ cells $\left(\mathrm{CD} 3^{+} \mathrm{CD} 4^{+}\right.$cells $)$and cytotoxic $\mathrm{T}\left(\mathrm{T}_{\mathrm{C}}\right)$ cells $\left(\mathrm{CD}^{+} \mathrm{CD}^{+}\right.$cells $)$. As the bridge between cellular immunization and humoral immunization, activated $\mathrm{T}_{\mathrm{H}}$ cells were also assessed by means of CD69 expression, the activation marker. All the results showed that the complexes displayed a synergistic effect, which indicates that
A

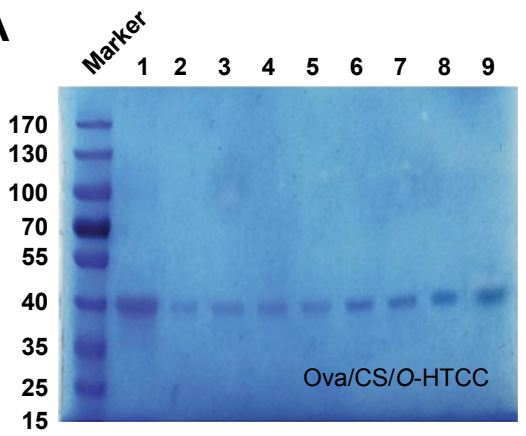

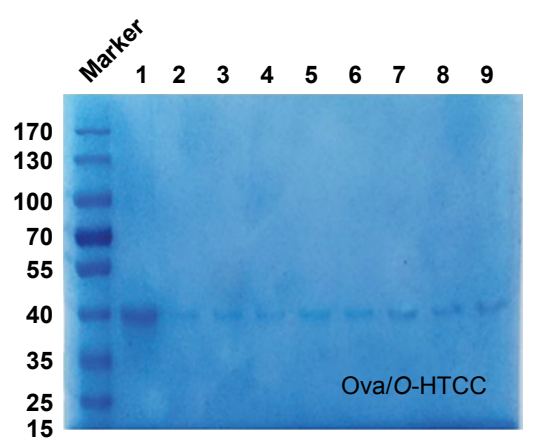

B

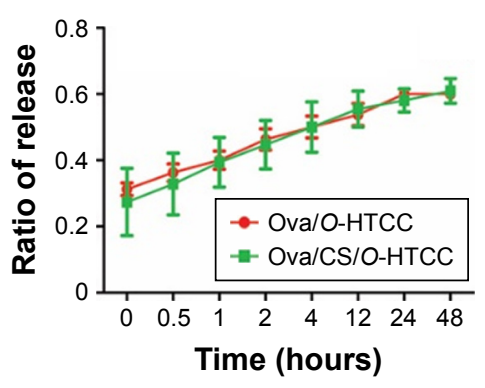

Figure 3 In vitro release of the complexes.

Notes: (A) Sodium dodecyl sulfate polyacrylamide gel electrophoresis of Ova released from the complexes: lane 1, Ova; lanes 2-9, Ova release from 0 to 48 hours. (B) Analysis of Ova release in the complexes $(n=3)$.

Abbreviations: Ova, ovalbumin; CS, curdlan sulfate; O-HTCC, O-(2-hydroxyl)propyl-3-trimethyl ammonium chitosan chloride. 
A
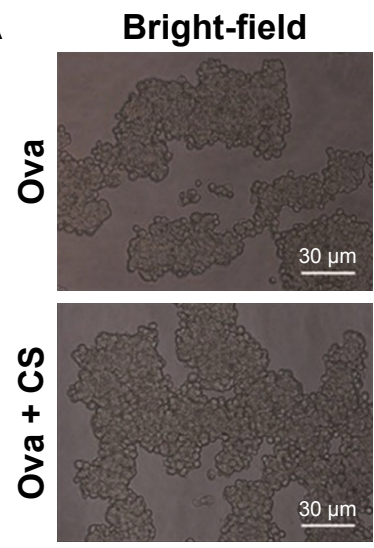

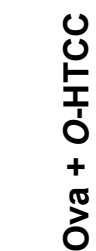

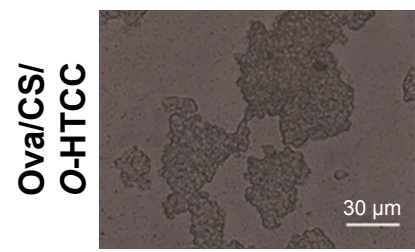

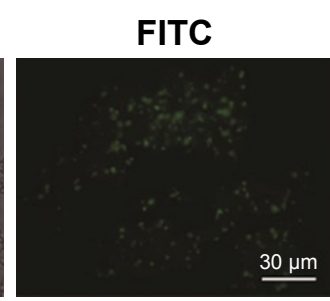
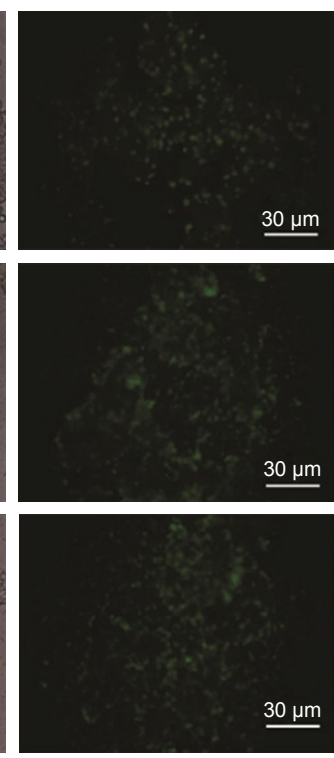

Merge
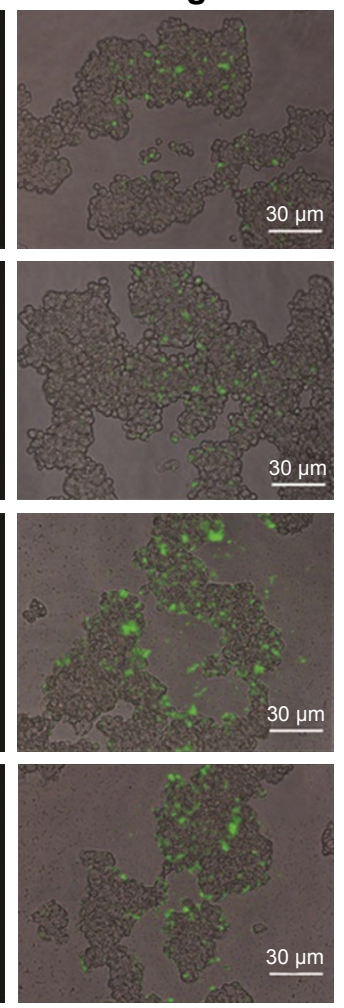

B

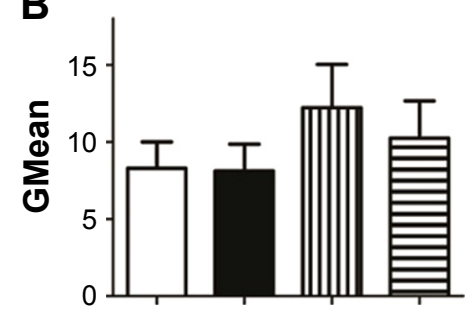

$\square$ Ova

$\square$ Ova + CS

III Ova + O-HTCC

曰 Ova/CS/O-HTCC

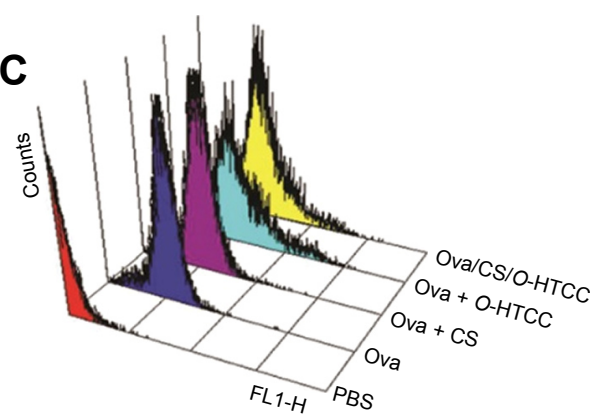

Figure 4 Uptake ability of FITC-Ova-loaded complexes.

Notes: (A) Fluorescence microscopy analysis of FITC-Ova uptake (400x); (B) quantification of cell uptake of FITC-Ova ( $\mathrm{n=3}$ ); (C) representative flow cytometry results of cell uptake ability.

Abbreviations: FITC, fluorescein isothiocyanate; CS, curdlan sulfate; O-HTCC, O-(2-hydroxyl)propyl-3-trimethyl ammonium chitosan chloride; Ova, ovalbumin.

$\mathrm{CS} / O$-HTCC notably improved the transformation and activation of antigen-specific $\mathrm{T}_{\mathrm{H}}$ and $\mathrm{T}_{\mathrm{C}}$ cells $(P<0.001)$.

The activation of APCs, such as dendritic cells and macrophages, is indispensable in stimulating lymphocytes. Curdlan has been proven to activate dendritic cells and increase the production of cytokines through dectin 1 and TLR $4 .{ }^{13}$ Chitosan can activate the NLRP3 inflammasome of macrophages ${ }^{34}$ and induce dendritic cell activation to promote $\mathrm{T}_{\mathrm{H}}$ 1-cell immunoresponses. In this study, the impact of the complexes upon the activation of APCs was studied.

As shown in Figure 6A, macrophages were stimulated by the polysaccharides, resulting in significant proliferation in all treatment groups, especially in the $O$-HTCC-related groups (Ova $+O$-HTCC group, $\mathrm{CS}+O$-HTCC group, and $\mathrm{Ova} / \mathrm{CS} / \mathrm{O}-\mathrm{HTCC}$ group). The phagocytic abilities of peritoneal macrophages extracted from immunized mice were detected by neutral red ingestion. Absorption values at $540 \mathrm{~nm}$ indicated that the number of absorbed particles significantly increased in the $O$-HTCC-related groups compared to the Ova group $(P<0.001$, Figure 6B), while no apparent effect was observed for the coadministration of Ova and Alhydrogel ( $P>0.05$ compared to Ova alone).
F4/80 binding to macrophages has been proven to be a specific macrophage marker. ${ }^{35}$ In this study, the proportion of F4/80-positive splenocytes indicated the recruitment of macrophages in the spleens of the immunized mice. As shown in Figure 6C, compared to Ova and Ova mixed with Alhydrogel, administration of the $O$-HTCC-related nanoparticles, especially $\mathrm{Ova} / \mathrm{CS} / O$-HTCC, induced a notable influx of macrophages in the spleen $(P<0.001$ compared to Ova alone, $P<0.01$ compared to Ova + Alhydrogel).

Internalization of the FITC-Ova in APCs was evaluated in vitro. The results in Figure $\mathrm{S} 4$ show that $O$-HTCC and $\mathrm{CS} / O$-HTCC provoked cellular uptake of the dendritic cells and peritoneal macrophages. After absorbing and processing the antigens, activated APCs present peptides to $\mathrm{CD} 4^{+} \mathrm{T}$ cells by the MHCII molecule, the ligand for the T-cell receptor, while recognition of peptide MHCII is insufficient for the activation of Ag-specific CD4+ $\mathrm{T}$ cells. ${ }^{36}$ As the costimulatory signal, CD40 induces the aggregation of MHCII molecules and the formation of the immunological synapse on APCs. ${ }^{37}$ The upregulation of CD86, an initial ligand for CD28, can lead to T-cell activation. ${ }^{38}$ The upregulation of CD11c indicates the transfer of dendritic cells to the spleen. Only the 
A
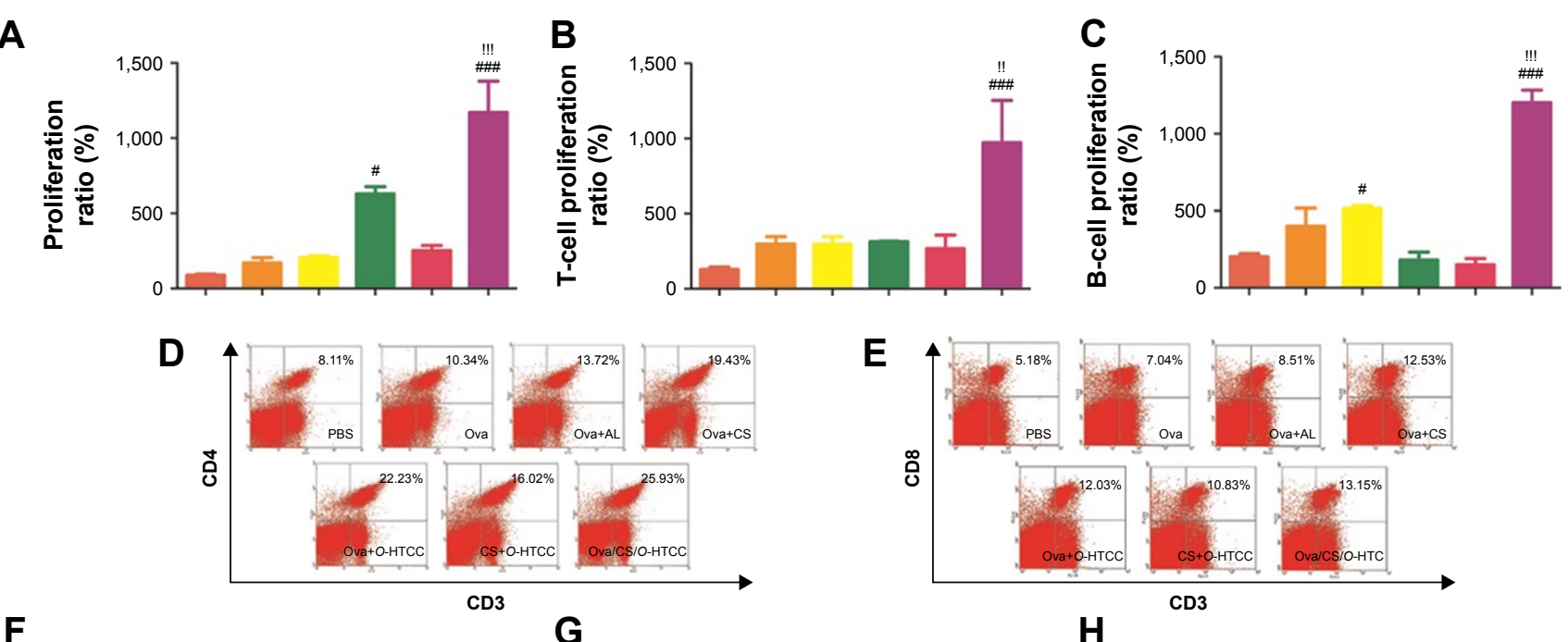

$\mathbf{F}$

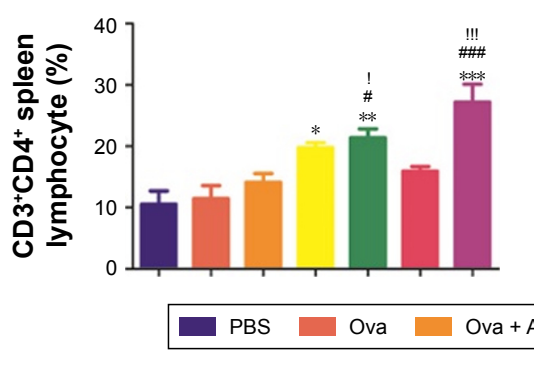

Figure 5 Effect of Ova-related complexes on lymphocytes.

Notes: (A) Spleen-lymphocyte proliferation; (B) T-lymphocyte transformation; (C) B-lymphocyte transformation; (D) flow cytometry results of proportion of CD3 ${ }^{+}$CD4 ${ }^{+}$ lymphocytes; (E) flow cytometry results of proportion of $\mathrm{CD} 3^{+} \mathrm{CD} 8^{+}$lymphocytes; (F) quantification of proportion of $\mathrm{CD} 3^{+} \mathrm{CD} 4^{+}$lymphocytes; (G) quantification of proportion of $\mathrm{CD}^{+}{ }^{+} \mathrm{CD} 8^{+}$lymphocytes; $(\mathbf{H})$ proportion of $C D 4+C D 69+$ lymphocytes. $* P<0.05$, $* * P<0.01$, $* * * P<0.00$ l compared to $P B S$ controls; ${ }^{\#} P<0.05$, ${ }^{*} P<0.0$, \#\# $P<0.00$ I compared to Ova controls; : $P<0.05$, " $P<0.0$ I, "':P<0.00I compared to Ova + AL controls $(n=3)$.

Abbreviations: CS, curdlan sulfate; O-HTCC, O-(2-hydroxyl)propyl-3-trimethyl ammonium chitosan chloride; Ova, ovalbumin; AL, Alhydrogel.

$\mathrm{CS} / O$-HTCC and $\mathrm{Ova} / \mathrm{CS} / O$-HTCC nanoparticles greatly stimulated the migration of dendritic cells to the spleen (Figure 6D). Analysis of the expression of costimulatory molecules (Figure $6 \mathrm{E}-\mathrm{G}$ ) revealed that $\mathrm{Ova} / \mathrm{CS} / \mathrm{O}-\mathrm{HTCC}$ significantly improved the maturation of dendritic cells.

According to these results, $\mathrm{CS} / O$-HTCC nanoparticles increased the influx of macrophages and dendritic cells into the spleen and improved phagocytosis, followed by activation of APCs to present peptides to T lymphocytes. After receiving the signal, inactive lymphocytes were activated and transformed to $T_{H}$ and $T_{C}$ cells with massive proliferation. Then, activated $\mathrm{CD} 4^{+} \mathrm{T}$ cells were chosen to regulate the immunoresponse.

Based on the secreted cytokines, effector $\mathrm{CD}^{+} \mathrm{T}$ cells can be divided into $\mathrm{T}_{\mathrm{H}} 1$ and $\mathrm{T}_{\mathrm{H}} 2$ cells. The $\mathrm{T}_{\mathrm{H}} 1$ cells produce proinflammatory cytokines (such as IFN $\gamma$ ), which are responsible for the activation of macrophages and $\mathrm{T}_{\mathrm{C}}$ cells. In contrast, $\mathrm{T}_{\mathrm{H}} 2$ cells produce IL4 and IL10 to promote humoral immunity. After analysis of the expression of IFN $\gamma$ in serum, only Ova/CS/O-HTCC was shown to increase IFN $\gamma$ concentration dramatically compared to PBS and Ova (Figure 7A,
$P<0.05$ ), which indicated that $\mathrm{CS} / O$-HTCC nanoparticles enhanced the $\mathrm{T}_{\mathrm{H}} 1$-type cellular immunoresponse to Ova. As specific $\mathrm{T}_{\mathrm{H}}$ 2-cell activators, Ova and Alhydrogel notably promoted the expression of IL4 (Figure 7B, $P<0.05$ compared to PBS), indicating that CS was also apt to enhance the $\mathrm{T}_{\mathrm{H}}$ 2-type immunoresponse. According to these results, Ova/CS/O-HTCC significantly activated both $\mathrm{T}_{\mathrm{H}} 1-$ and $\mathrm{T}_{\mathrm{H}}$ 2-type cellular immunoresponses. However, compared to the Ova-induced $\mathrm{T}_{\mathrm{H}} 2$ bias, Ova/CS/O-HTCC recovered the balance to some extent.

\section{Effect of Ova/CS/O-HTCC on promoting humoral immunoresponses}

As effector molecules secreted by plasma cells, antibodies play an important role in the defense against extracellular microbes. IgG accounts for $\sim 75 \%$ of the total immunoglobulins in plasma. A positive result was determined by a ratio of the absorbance of the tested (positive) serum and negative serum $(\mathrm{P}: \mathrm{N})$ of $>2.1$. The maximum dilution is called the titer of antibody for the antiserum when the $\mathrm{P}: \mathrm{N}$ is $\geq 2.1$. As shown in Figure 8A, after the primary immunization, 


\section{A}

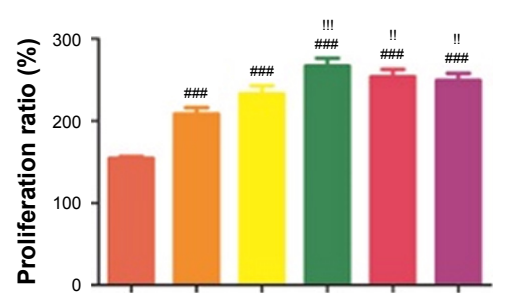

D

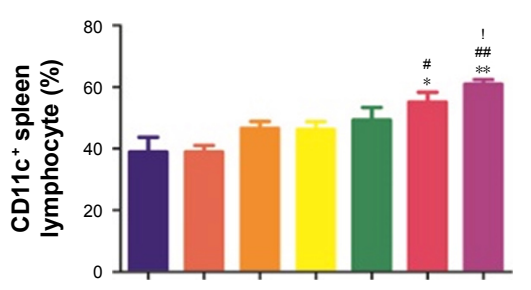

B

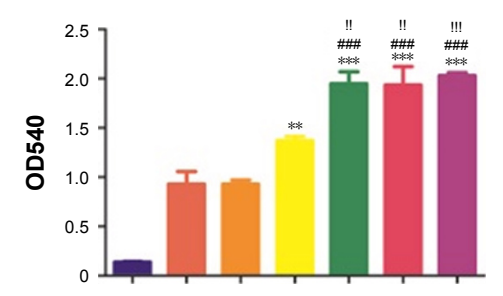

E

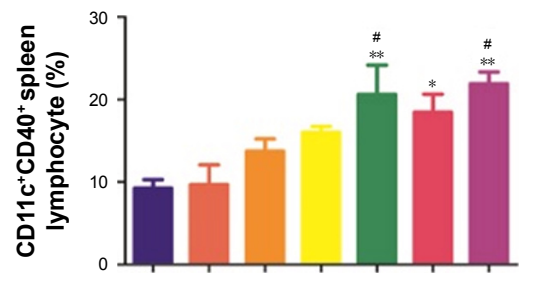

G

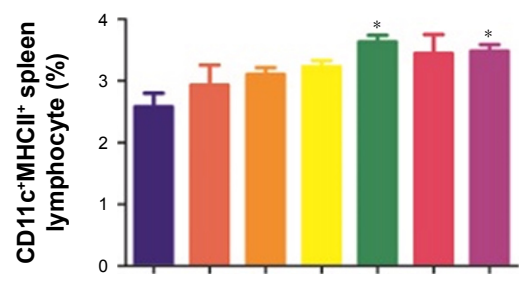

C

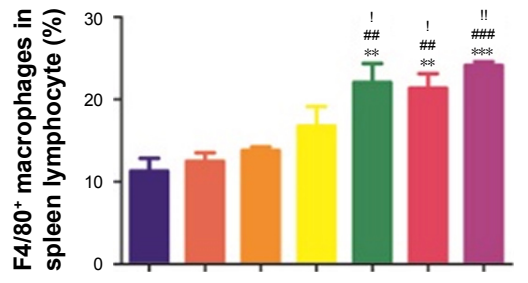

$\mathbf{F}$

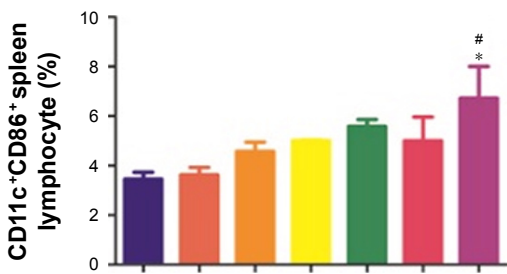

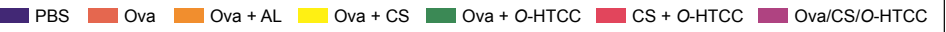

Figure 6 Effect of Ova-related complexes on antigen-presenting cells.

Notes: (A) Macrophage proliferation; (B) macrophage phagocytosis; (C) proportion of F4/80+ macrophages; (D) proportion of CDII $\mathrm{c}^{+}$splenocytes; (E) proportion of

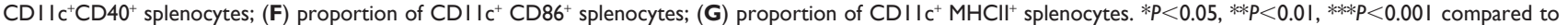

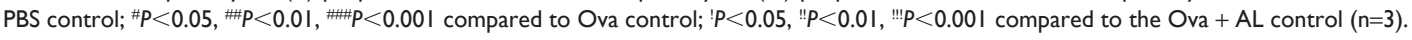

Abbreviations: CS, curdlan sulfate; $\mathrm{O}$-HTCC, O-(2-hydroxyl)propyl-3-trimethyl ammonium chitosan chloride; Ova, ovalbumin; AL, Alhydrogel; MHC, major histocompatibility complex.

the IgG concentration significantly increased in the serum of the Ova/CS/O-HTCC group compared to the PBS group $(P<0.001)$. In contrast, the production of IgG in the other immunized groups did not notably change $(P>0.05)$. IgG expression in serum was greatly elevated by the second and third challenges. As a positive control, Alhydrogel showed a high level of Ova-specific IgG titers after the secondary immunization $(P<0.05$ compared to Ova), while the mice
A

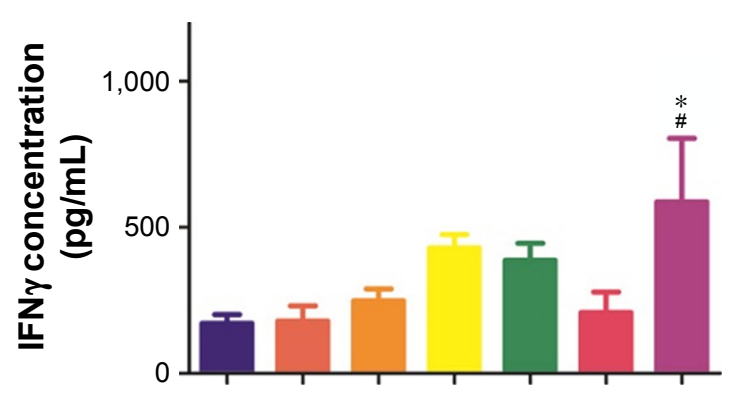

B

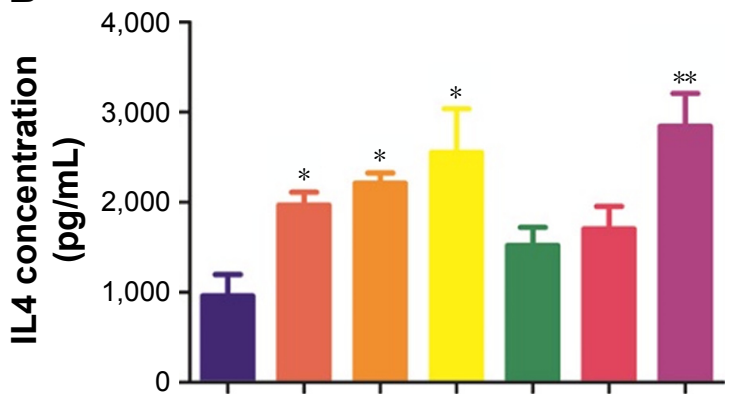

PBS Ova Ova + AL Ova + CS Ova + O-HTCC CS + O-HTCC Ova/CS/O-HTCC

Figure 7 Expression level of cytokines.

Notes: (A) IFN $\gamma$ concentration; (B) IL4 concentration. $* P<0.05$, $* * P<0.01$ compared to PBS control; ${ }^{*} P<0.05$ compared to Ova control ( $\mathrm{n}=3$ ). Abbreviations: CS, curdlan sulfate; O-HTCC, O-(2-hydroxyl)propyl-3-trimethyl ammonium chitosan chloride; Ova, ovalbumin; AL, Alhydrogel. 
A

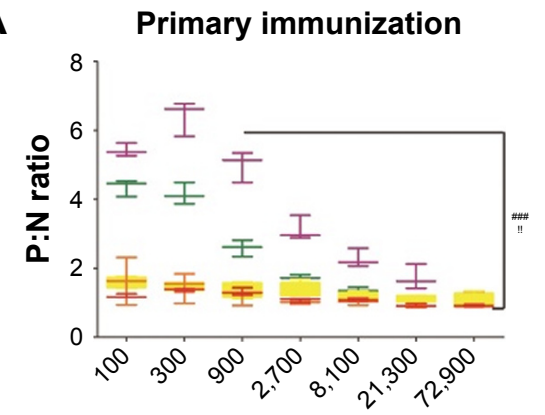

Dilution

B

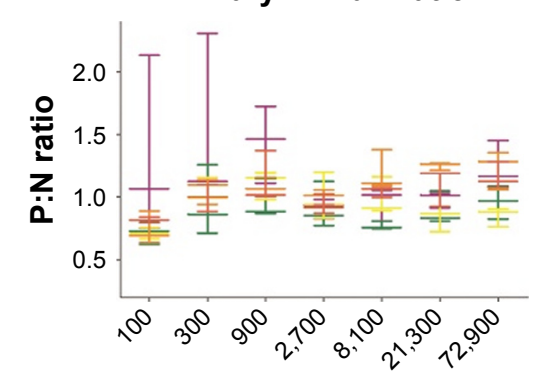

Dilution

\section{C}

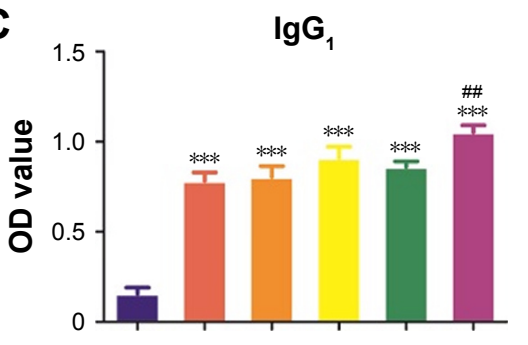

Secondary immunization

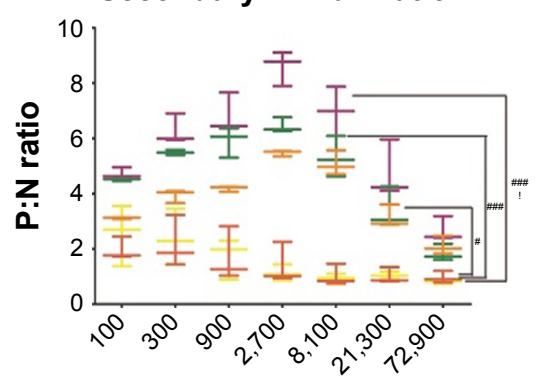

Dilution

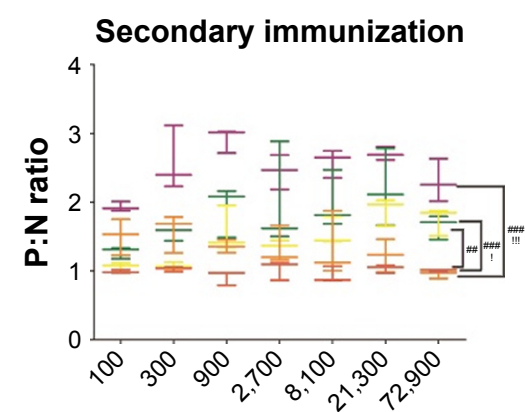

Dilution

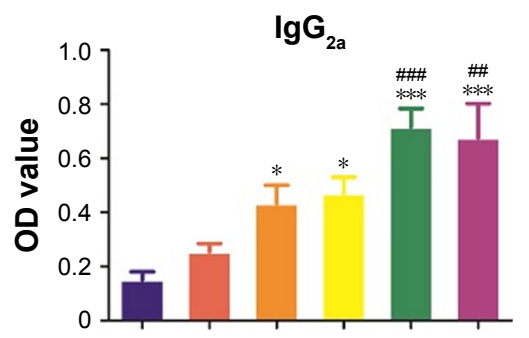

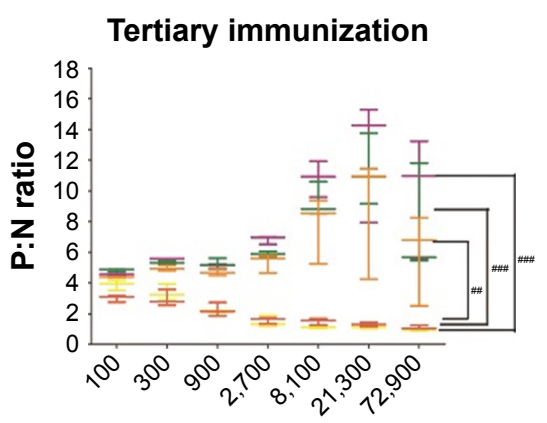

Dilution

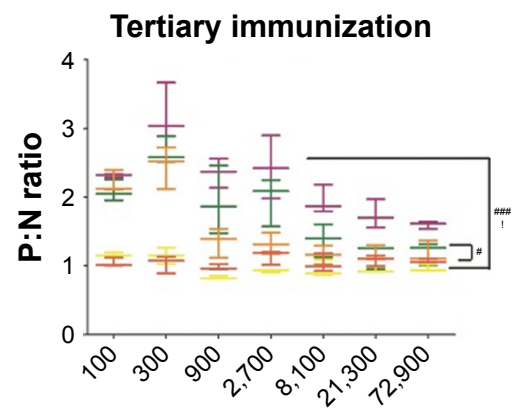

Dilution

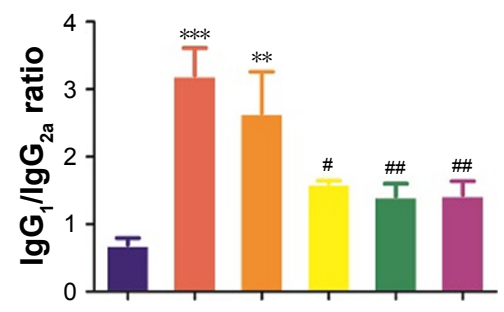

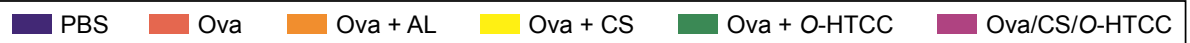

Figure 8 Humoral immunoresponse of immunized mice.

Notes: (A) Relative expression of IgG in serum; (B) relative expression of IgA in serum; (C) expression of subtype antibodies in serum. $* P<0.05$, $* * P<0.01$, $* * * P<0.001$ compared to PBS control; ${ }^{P} P<0.05,{ }^{\# P}<0.01,{ }^{\# P} P<0.00$ I compared to Ova control; $: P<0.05, ": P<0.01$ compared to Ova $+A L$ control ( $n=8$ ).

Abbreviations: $\mathrm{CS}$, curdlan sulfate; $\mathrm{O}-\mathrm{HTCC}, \mathrm{O}-(2$-hydroxyl)propyl-3-trimethyl ammonium chitosan chloride; Ova, ovalbumin; AL, Alhydrogel.

immunized with Ova/CS/O-HTCC produced a marked antibody response compared to the mice treated with Ova mixed with Alhydrogel $(P<0.05)$.

$\operatorname{IgA}$, a specific antibody produced by mucosal immunity, was also detected in serum (Figure 8B). Although the antibody titer was significantly higher in the Ova mixed with Alhydrogel-treatment group and Ova/O-HTCC-treatment group after the primary inoculum, mice receiving Ova/ $\mathrm{CS} / \mathrm{O}$-HTCC showed much higher levels of anti-Ova titers after the second and the third antigen inoculum $(P<0.001$ compared to Ova). Expression of the antigen-specific $\operatorname{IgG}_{1}$ and $\operatorname{IgG}_{2 \mathrm{a}}$ subclasses was evaluated 2 weeks after the tertiary immunization. As shown in Figure 8C, in contrast to Ova and Alhydrogel, which only increased the production of $\mathrm{IgG}_{1}$,
Ova/O-HTCC and Ova/CS/O-HTCC increased the production of both $\mathrm{IgG}_{1}$ and $\mathrm{IgG}_{2 \mathrm{a}}$. By the ratio between $\mathrm{IgG}_{1}$ and $\mathrm{IgG}_{2 \mathrm{a}}$, ratios immunized with $\mathrm{CS}, \mathrm{O}$-HTCC, and $\mathrm{CS} / O$-HTCC adjuvant vaccines were approximately a third that of Ova alone. Therefore, $\mathrm{CS}$ and $O$-HTCC alleviated the strong bias toward a $\mathrm{T}_{\mathrm{H}}$ 2-type response induced by Ova.

\section{Effect of Ova/CS/O-HTCC on proximal mucosa and distal mucosa immunoresponse}

Site-specific integrins on sensitized mucosal immunocytes and the chemokines produced in vaccine-exposed mucosa impact the effector site. ${ }^{39}$ After nasal mucosal immunization, an immunoresponse would occur directly in the mucosa of the 


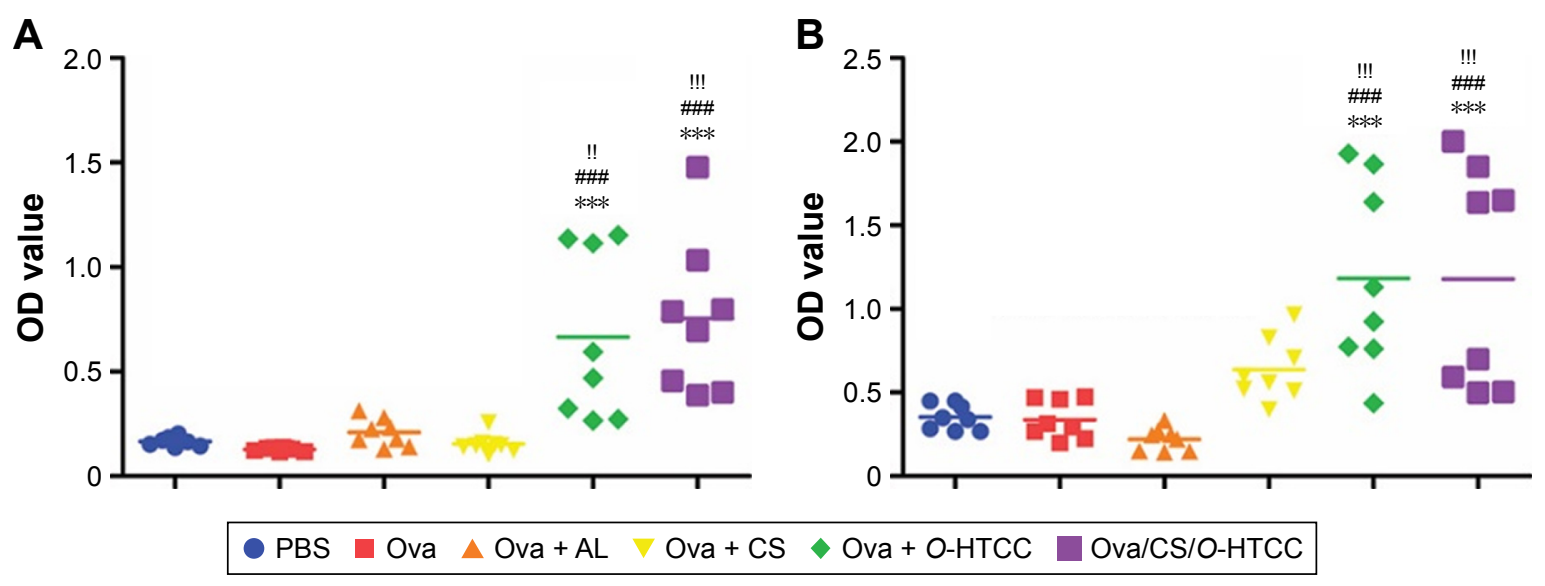

Figure 9 Mucosal immunoresponse of immunized mice.

Notes: (A) Expression of secretory IgA in saliva; (B) expression of secretory IgA in vaginal lavage fluid. $* * * P<0.00$ I compared to $P B S$ control; ${ }^{\# \#} P<0.00$ I compared to Ova control; " $P<0.01$, "' $P<0.00$ I compared to the Ova $+A L$ control $(n=8)$.

Abbreviations: CS, curdlan sulfate; O-HTCC, O-(2-hydroxyl)propyl-3-trimethyl ammonium chitosan chloride; Ova, ovalbumin; AL, Alhydrogel.

nasal cavity, as well as in the adjacent oral mucosa. Simultaneously, this immunization route also stimulates a strong vaginal mucosal immunoresponse. ${ }^{40}$ As the key effector of mucosal immunity, sIgA was tested in the saliva and vaginal lavage fluid after 2 weeks of tertiary immunization (Figure 9). $O$-HTCC and CS/O-HTCC significantly boosted the expression of $\operatorname{sIgA}$ in both the saliva and the vagina compared to Ova alone $(P<0.001)$. In contrast, Ova-specific sIgA was not detectable in the Ova mixed with the Alhydrogel group. The results illustrate that Ova-loaded nanoparticles are a potential candidate as an effective nasal immunoadjuvant of vaccines against respiratory viruses or female genital viruses.

\section{Conclusion}

In consideration of the immunogenicity of polysaccharides, in this investigation two types of modified polysaccharides with special immunoactivity, $\mathrm{CS}$ and $O$-HTCC, were prepared successfully. CS and $O$-HTCC were mixed and interacted by electrostatic absorption, forming a new type of mucosal adjuvant: $\mathrm{CS} / O$-HTCC nanoparticles. Ova, a model antigen, was entrapped by $\mathrm{CS} / O$-HTCC under mild conditions, and positively charged Ova/CS/O-HTCC $(11.8 \mathrm{mV})$ spherical particles $(178 \mathrm{~nm})$ were obtained. To determine whether the complexes could be ingested, an in vitro epithelial cell culture as a nasal mucosa model was used to test uptake ability. The results indicated that the positively charged complexes notably adhered on the mucosal surface and were immediately adsorbed by the epithelial cells. When administered by nasal mucosa dripping, $\mathrm{CS} / O$-HTCC as an immunopotentiator and protein carrier activated APCs to present and make full use of the antigens and further enhance the cellular humoral activity of Ova. Remarkably, Ova/CS/ $O$-HTCC significantly elicited the expression level of sIgA in vaginal lavage fluid, which indicated our designed nanocarrier can evoke a strong distal mucosa immunoresponse. Moreover, CS/O-HTCC ameliorated the strong bias toward an Ova-induced $\mathrm{T}_{\mathrm{H}}$ 2-type response, thereby reducing allergic reactions. The results prove that the Ova-loaded nanoparticles (Ova/CS/O/HTCC) have the potential to act as an effective nasal mucosal vaccine adjuvant. The safety and prevention of infectious pathogens should be evaluated in the future.

\section{Acknowledgments}

This work was supported by grants from the National Natural Science Foundation of China (81603011), Major Projects of Science and Technology of Shandong Province (No 2015ZDJS04001), and the Taishan Scholar Scheme of Shandong Province of China (Special Term Expert for Pharmacy, 2012GSF30022).

\section{Disclosure}

The authors report no conflicts of interest in this work.

\section{References}

1. Brokstad KA, Eriksson JC, Cox RJ, et al. Parenteral vaccination against influenza does not induce a local antigen-specific immune response in the nasal mucosa. J Infect Dis. 2002;185(7):878-884.

2. Wu HY, Nguyen HH, Russell MW. Nasal lymphoid tissue (NALT) as a mucosal immune inductive site. Scand J Immunol. 1997;46(5): 506-513.

3. Tacchi L, Musharrafieh R, Larragoite ET, et al. Nasal immunity is an ancient arm of the mucosal immune system of vertebrates. Nat Commun. 2014;5:5205.

4. Poliquin JF, Crepeau J. Immune defence mechanisms of the nasal mucosa. J Otolaryngol. 1985;14(2):80-84. 
5. Neutra MR, Kozlowski PA. Mucosal vaccines: the promise and the challenge. Nat Rev Immunol. 2006;6(2):148-158.

6. Zhao L, Seth A, Wibowo N, et al. Nanoparticle vaccines. Vaccine. 2014; 32(3):327-337.

7. Zhu M, Wang R, Nie G. Applications of nanomaterials as vaccine adjuvants. Hum Vaccin Immunother. 2014;10(9):2761-2774.

8. Ryan EJ, Daly LM, Mills KH. Immunomodulators and delivery systems for vaccination by mucosal routes. Trends Biotechnol. 2001; 19(8):293-304.

9. Chen L, Zhu J, Li Y, et al. Enhanced nasal mucosal delivery and immunogenicity of anti-caries DNA vaccine through incorporation of anionic liposomes in chitosan/DNA complexes. PLoS One. 2013;8(8): e71953.

10. Sloat BR, Cui Z. Nasal immunization with a dual antigen anthrax vaccine induced strong mucosal and systemic immune responses against toxins and bacilli. Vaccine. 2006;24(40-41):6405-6413.

11. Zeng L. Mucosal adjuvants: opportunities and challenges. Hum Vaccin Immunother. 2016;12(9):2456-2458.

12. Ferwerda G, Meyer-Wentrup F, Kullberg BJ, Netea MG, Adema GJ. Dectin-1 synergizes with TLR2 and TLR4 for cytokine production in human primary monocytes and macrophages. Cell Microbiol. 2008; 10(10):2058-2066.

13. Kim HS, Park KH, Lee HK, et al. Curdlan activates dendritic cells through dectin-1 and toll-like receptor 4 signaling. Int ImmunoPharmacol. 2016; 39:71-78.

14. Li P, Zhang X, Cheng Y, et al. Preparation and in vitro immunomodulatory effect of curdlan sulfate. Carbohydr Polym. 2014;102:852-861.

15. Li P, Tan H, Xu D, et al. Effect and mechanisms of curdlan sulfate on inhibiting $\mathrm{HBV}$ infection and acting as an $\mathrm{HB}$ vaccine adjuvant. Carbohydr Polym. 2014;110:446-455.

16. Kyriacou HM, Steen KE, Raza A, et al. In vitro inhibition of Plasmodium falciParum rosette formation by curdlan sulfate. Antimicrob Agents Chemother. 2007;51(4):1321-1326.

17. Ichiyama K, Reddy SB, Zhang LF, et al. Sulfated polysaccharide, curdlan sulfate, efficiently prevents entry/fusion and restricts antibodydependent enhancement of dengue virus infection in vitro: a possible candidate for clinical application. PLoS Negl TroP Dis. 2013; 7(4):e2188.

18. Sadeghi AM, Dorkoosh FA, Avadi MR, et al. Permeation enhancer effect of chitosan and chitosan derivatives: comparison of formulations as soluble polymers and nanoparticulate systems on insulin absorption in Caco-2 cells. Eur J Pharm BioPharm. 2008;70(1):270-278.

19. Nagpal K, Singh SK, Mishra DN. Chitosan nanoparticles: a promising system in novel drug delivery. Chem Pharm Bull (Tokyo). 2010; 58(11):1423-1430.

20. van der Merwe SM, Verhoef JC, Verheijden JH, Kotzé AF, Junginger HE. Trimethylated chitosan as polymeric absorption enhancer for improved peroral delivery of peptide drugs. Eur J Pharm BioPharm. 2004; 58(2):225-235.

21. van der Merwe SM, Verhoef JC, Kotzé AF, Junginger HE. N-trimethyl chitosan chloride as absorption enhancer in oral peptide drug delivery: development and characterization of minitablet and granule formulations. Eur J Pharm BioPharm. 2004;57(1):85-91.

22. Thanou MM, Verhoef JC, Romeijn SG, Nagelkerke JF, Merkus FW, Junginger HE. Effects of N-trimethyl chitosan chloride, a novel absorption enhancer, on caco-2 intestinal epithelia and the ciliary beat frequency of chicken embryo trachea. Int J Pharm. 1999;185(1):73-82.
23. Sahni JK, Chopra S, Ahmad FJ, Khar RK. Potential prospects of chitosan derivative trimethyl chitosan chloride (TMC) as a polymeric absorption enhancer: synthesis, characterization and applications. J Pharm Pharmacol. 2008;60(9):1111-1119.

24. Kotze AF, Luessen HL, de Leeuw BJ, de Boer BG, Verhoef JC, Junginger HE. N-trimethyl chitosan chloride as a potential absorption enhancer across mucosal surfaces: in vitro evaluation in intestinal epithelial cells (Caco-2). Pharm Res. 1997;14(9):1197-1202.

25. Xu Y, Du Y, Huang R, Gao L. Preparation and modification of N-(2hydroxyl) propyl-3-trimethyl ammonium chitosan chloride nanoparticle as a protein carrier. Biomaterials. 2003;24(27):5015-5022.

26. Xu L, Ji X, Zhao N, Song C, Wang F, Liu C. The conjugation of Cu/ Zn superoxide dismutase (SOD) to O-(2-hydroxyl) propyl-3-trimethyl ammonium chitosan chloride (O-HTCC) enhances its therapeutic potential against radiation-induced oxidative damage. Polym Chem. 2016;7(9):1826-1835.

27. Yu Y, Sun F, Zhang C, Wang Z, Liu J, Tan H. Study on glyco-modification of endostatin-derived synthetic peptide endostatin 2 (ES2) by soluble chitooligosaccharide. Carbohydr Polym. 2016;154:204-213.

28. Sun Y, Wan A. Preparation of nanoparticles composed of chitosan and its derivatives as delivery systems for macromolecules. $J \mathrm{Appl}$ Polym Sci. 2007;105(2):552-561.

29. Zhang X, Goncalves R, Mosser DM. The isolation and characterization of murine macrophages. Curr Protoc Immunol. 2007;105(2):552-561.

30. Quan FS, Li ZN, Kim MC, et al. Immunogenicity of low-pH treated whole viral influenza vaccine. Virology. 2011;417(1):196-202.

31. Yusuf H, Kett V. Current prospects and future challenges for nasal vaccine delivery. Hum Vaccin Immunother. 2017;13(1):34-45.

32. Lai SK, Wang YY, Hanes J. Mucus-penetrating nanoparticles for drug and gene delivery to mucosal tissues. Adv Drug Deliv Rev. 2009; 61(2):158-171.

33. Sayin B, Somavarapu S, Li XW, et al. Mono-N-carboxymethyl chitosan (MCC) and N-trimethyl chitosan (TMC) nanoparticles for non-invasive vaccine delivery. Int J Pharm. 2008;363(1-2):139-148.

34. Bueter CL, Lee CK, Rathinam VA, et al. Chitosan but not chitin activates the inflammasome by a mechanism dependent upon phagocytosis. J Biol Chem. 2011;286(41):35447-35455.

35. Austyn JM, Gordon S. F4/80, a monoclonal antibody directed specifically against the mouse macrophage. Eur J Immunol. 1981;11(10): $805-815$.

36. van Gool SW, Vandenberghe P, de Boer M, Ceuppens JL. CD80, CD86 and CD40 provide accessory signals in a multiple-step T-cell activation model. Immunol Rev. 1996;153:47-83.

37. Clatza A, Bonifaz LC, Vignali DA, Moreno J. CD40-induced aggregation of MHC class II and CD 80 on the cell surface leads to an early enhancement in antigen presentation. J Immunol. 2003;171(12):6478-6487.

38. Sansom DM, Manzotti CN, Zheng Y. What's the difference between CD80 and CD86? Trends Immunol. 2003;24(6):314-319.

39. Kunkel EJ, Butcher EC. Plasma-cell homing. Nat Rev Immunol. 2003; $3(10): 822-829$

40. Johansson EL, Wassén L, Holmgren J, Jertborn M, Rudin A. Nasal and vaginal vaccinations have differential effects on antibody responses in vaginal and cervical secretions in humans. Infect Immun. 2001;69(12): 7481-7486. 


\section{Supplementary materials}

Table SI Immunization protocol

\begin{tabular}{lllllll}
\hline Formulation & $\begin{array}{l}\text { Antigen } \\
\text { dose }(\mu \mathrm{g})\end{array}$ & $\begin{array}{l}\text { Volume } \\
(\mu \mathrm{L})\end{array}$ & $\begin{array}{l}\text { Immunization } \\
\text { schedule } \\
\text { (days) }\end{array}$ & $\begin{array}{l}\text { Serum } \\
\text { (days) }\end{array}$ & $\begin{array}{l}\text { Saliva, vaginal } \\
\text { fluid (days) }\end{array}$ & $\begin{array}{l}\text { Immunocytes } \\
\text { (splenocytes, } \\
\text { macrophages) (days) }\end{array}$ \\
\hline PBS & 0 & 20 & I, I5, 29 & $14,28,42$ & 42 & 42 \\
Ova & 20 & 20 & I, I5, 29 & $14,28,42$ & 42 & 42 \\
Ova + AL & 20 & 20 & I, I5, 29 & $14,28,42$ & 42 & 42 \\
Ova + CS & 20 & 20 & I, I5, 29 & $14,28,42$ & 42 & 42 \\
Ova + O-HTCC & 20 & 20 & I, I5, 29 & $14,28,42$ & 42 & 42 \\
CS + O-HTCC & 0 & 20 & I, I5, 29 & $14,28,42$ & 42 & 42 \\
Ova/CS/O-HTCC & 20 & 20 & I, I5, 29 & $14,28,42$ & 42 & 42 \\
\hline
\end{tabular}

Abbreviations: CS, curdlan sulfate; O-HTCC, O-(2-hydroxyl)propyl-3-trimethyl ammonium chitosan chloride; Ova, ovalbumin; AL, Alhydrogel.

A

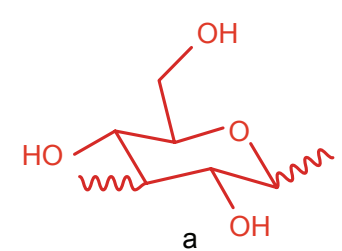

a

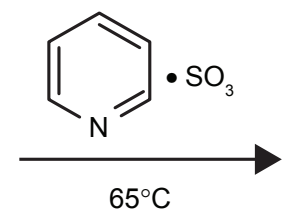

$65^{\circ} \mathrm{C}$

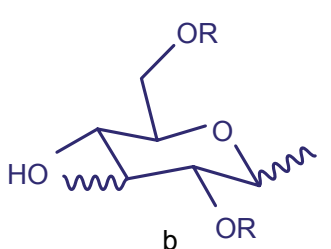

$\mathrm{R}=\mathrm{SO}_{3} \mathrm{Na}$ or $\mathrm{H}$

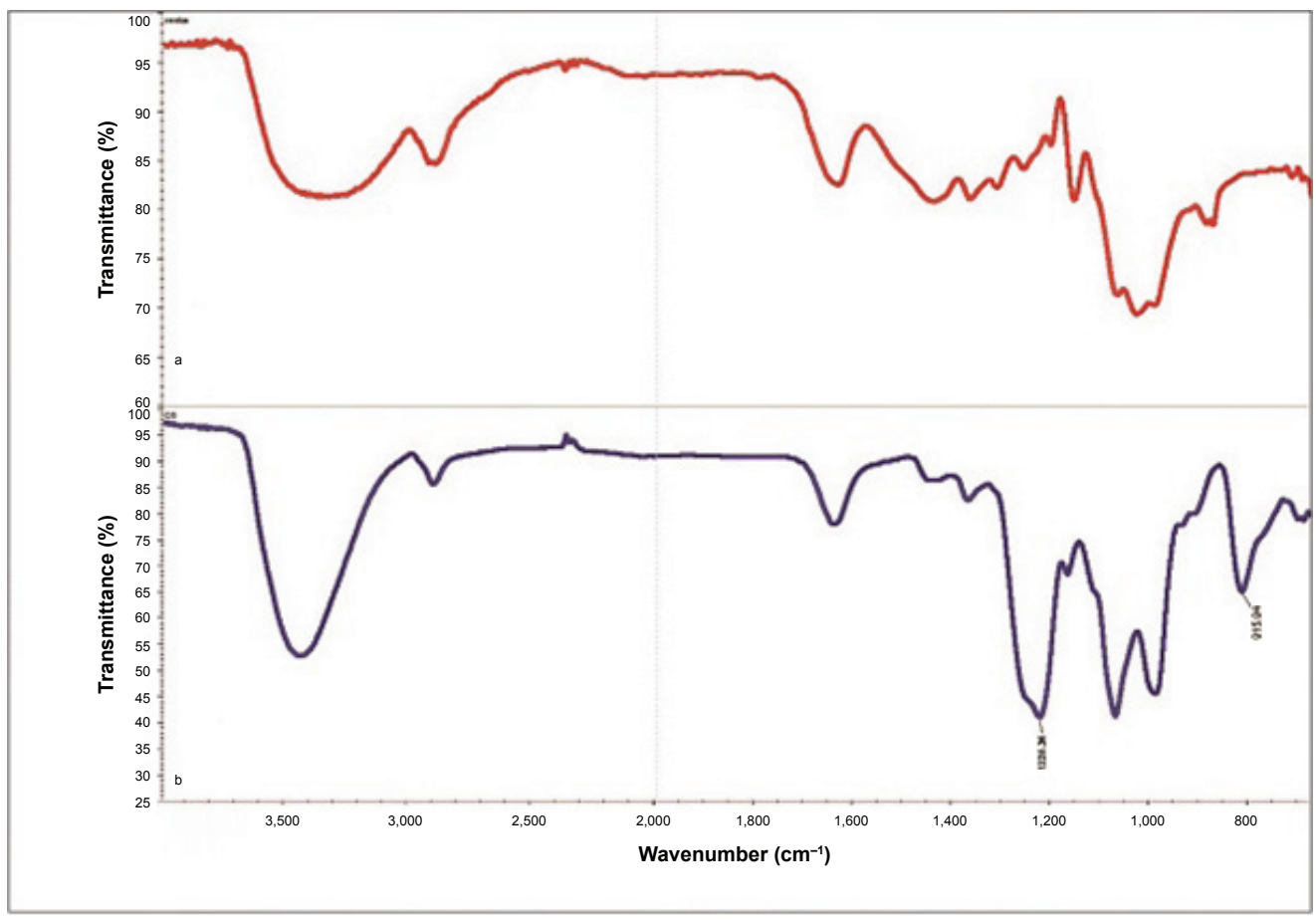

Figure SI (Continued) 


\section{B

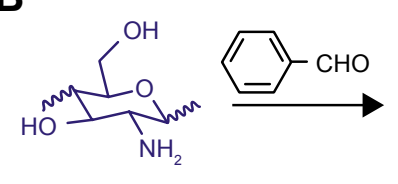

a
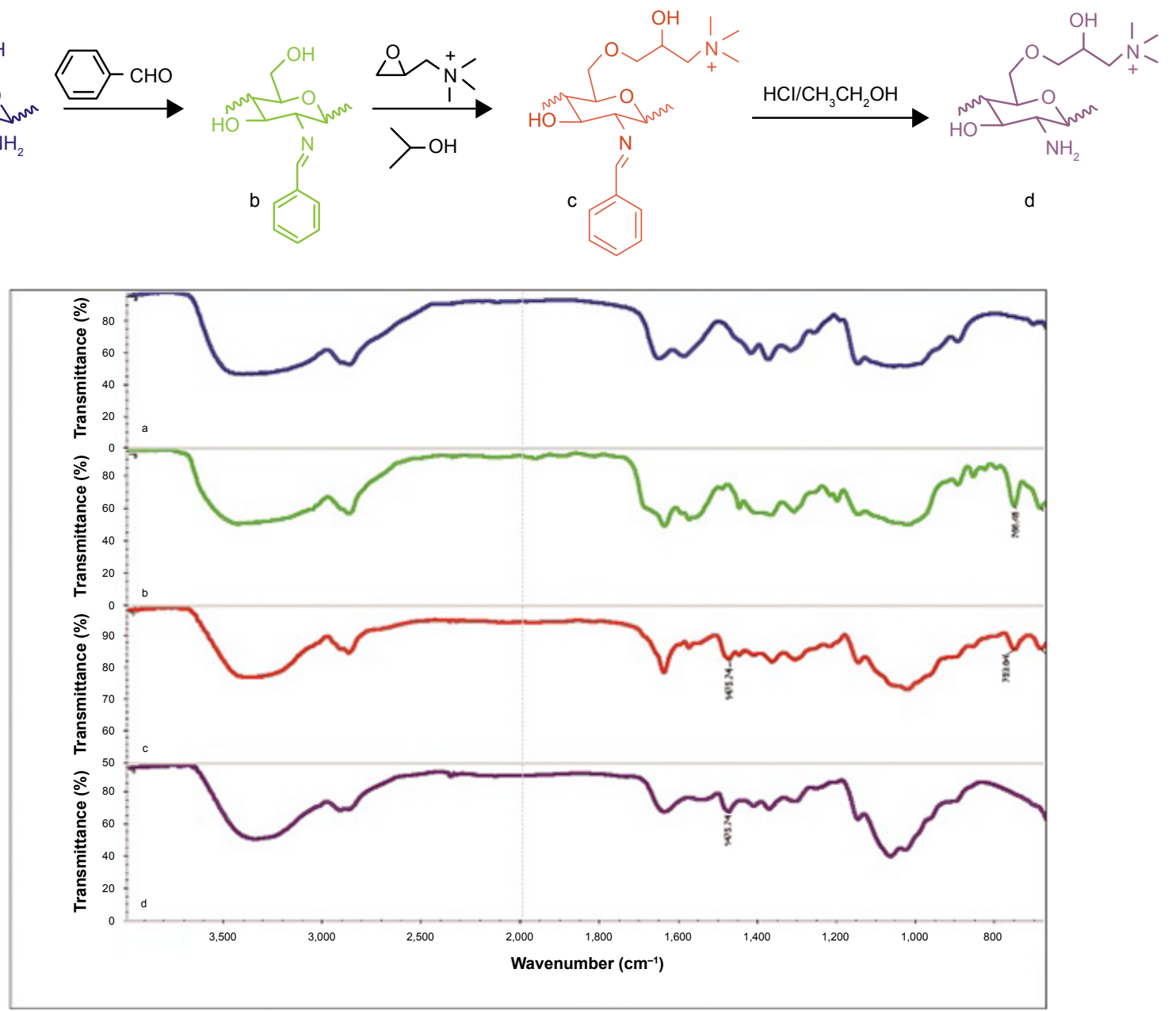

Figure SI Fourier transform infrared spectra of CS and O-HTCC.

Notes: (A) CS: a, curdlan; b, CS. (B) O-HTCC: a, chitosan; b, intermediate product b; c, intermediate product c; d, O-HTCC.

Abbreviations: CS, curdlan sulfate; O-HTCC, O-(2-hydroxyl)propyl-3-trimethyl ammonium chitosan chloride.

Table S2 Elemental analysis of curdlan and CS

\begin{tabular}{lllll}
\hline & $\mathbf{N}(\%)$ & $\mathbf{C}(\%)$ & $\mathbf{H}(\%)$ & $\mathbf{S}(\%)$ \\
\hline Curdlan & 1.32 & 37.77 & 6.13 & 0 \\
CS & 0.32 & 21.54 & 4.03 & 13.74
\end{tabular}

Abbreviation: CS, curdlan sulfate. 


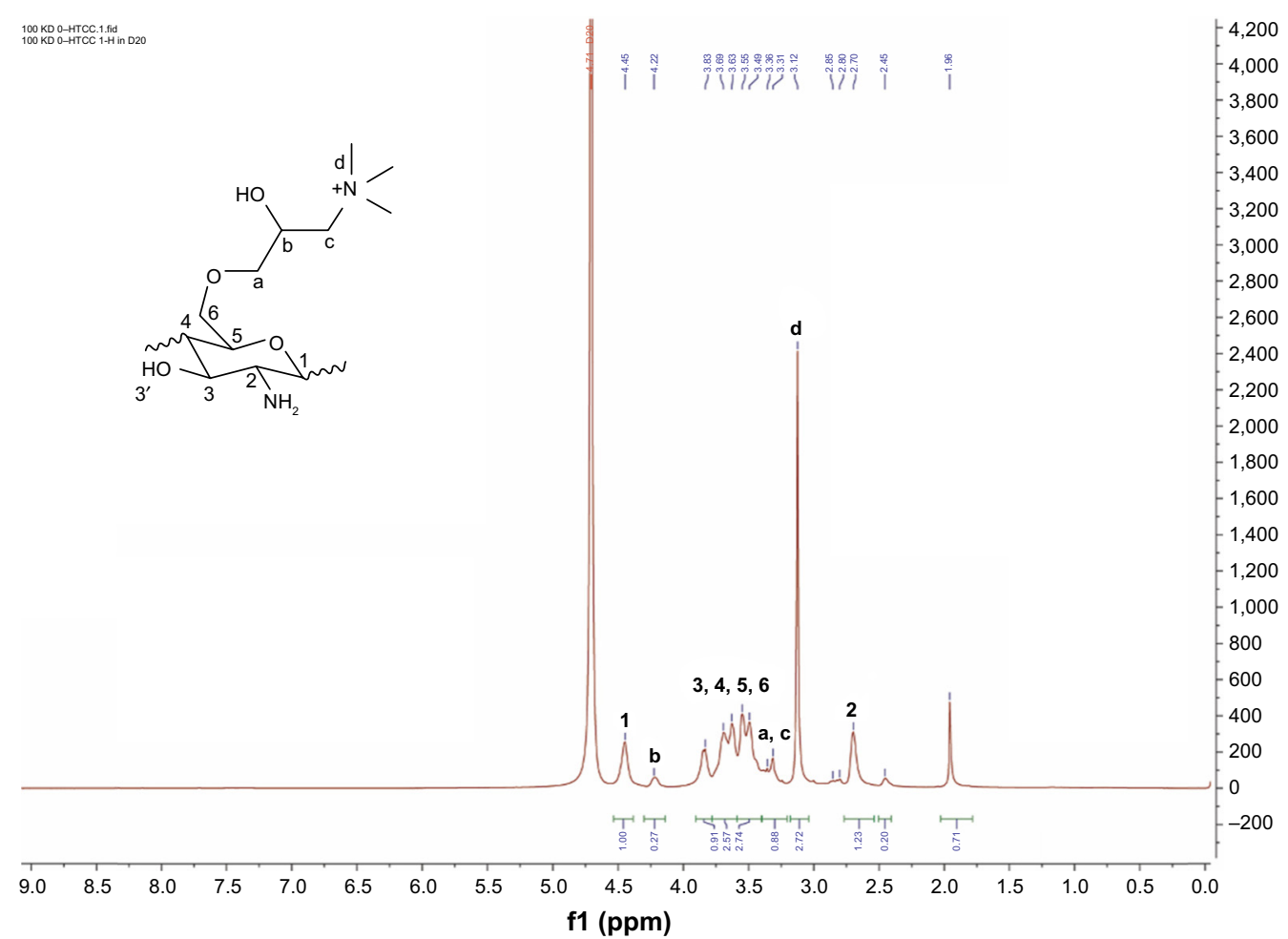

Figure S2 'H NMR spectra of O-HTCC: analysis of correspondence between structural units and peaks.

Abbreviations: 'H NMR, proton nuclear magnetic resonance; $\mathrm{O}-\mathrm{HTCC}, \mathrm{O}$-(2-hydroxyl)propyl-3-trimethyl ammonium chitosan chloride.

Table S3 Physicochemical properties of the complexes

\begin{tabular}{lllll}
\hline Formulation & Size $(\mathbf{n m})$ & PDI & $\zeta$-potential $(\mathbf{m V})$ & Loading efficiency $(\%)$ \\
\hline CS/O-HTCC & $167.03 \pm 5.88$ & $0.12 \pm 0.01$ & $50.10 \pm 0.85$ & - \\
Ova/CS/O-HTCC & $178 \pm 5.18$ & $0.08 \pm 0.02$ & $11.80 \pm 1.42$ & $72.60 \pm 2.21$ \\
Ova/O-HTCC & $507.37 \pm 65.52$ & $0.45 \pm 0.02$ & $17.80 \pm 1.11$ & $68.76 \pm 3.65$ \\
\hline
\end{tabular}

Note: Data presented as means $\pm S D, n=3$.

Abbreviations: PDI, polydispersity index; CS, curdlan sulfate; O-HTCC, O-(2-hydroxyl)propyl-3-trimethyl ammonium chitosan chloride; Ova, ovalbumin. 


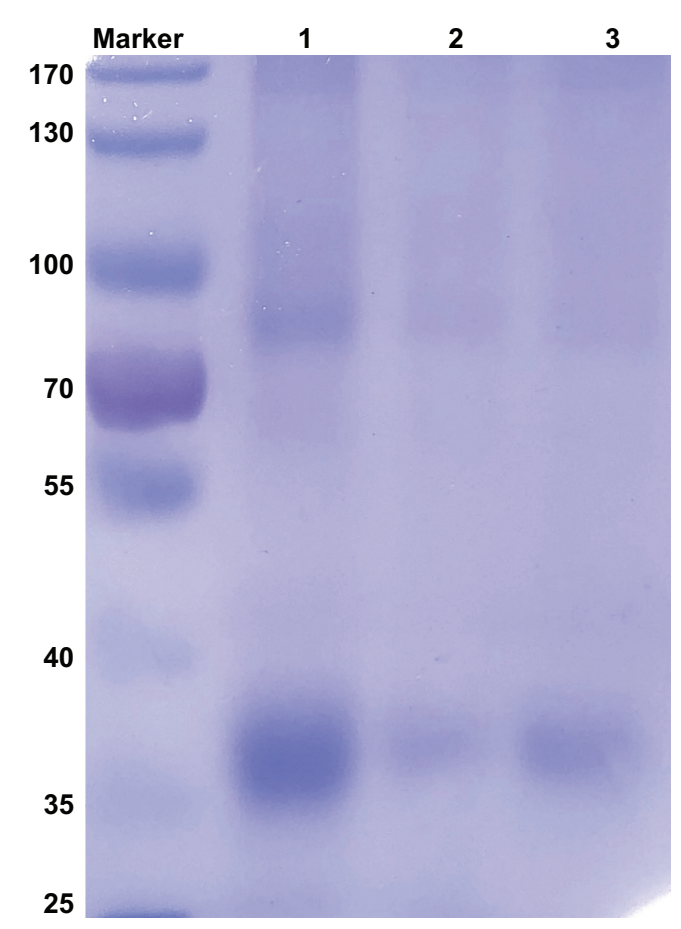

Figure S3 Loading efficiency of the complexes.

Notes: Sodium dodecyl sulfate polyacrylamide gel electrophoresis of unabsorbed Ova in the supernatants: lane I, Ova; lane 2, Ova/CS/O-HTCC; lane 3, Ova/O-HTCC. Abbreviations: CS, curdlan sulfate; O-HTCC, O-(2-hydroxyl)propyl-3-trimethyl ammonium chitosan chloride; Ova, ovalbumin.
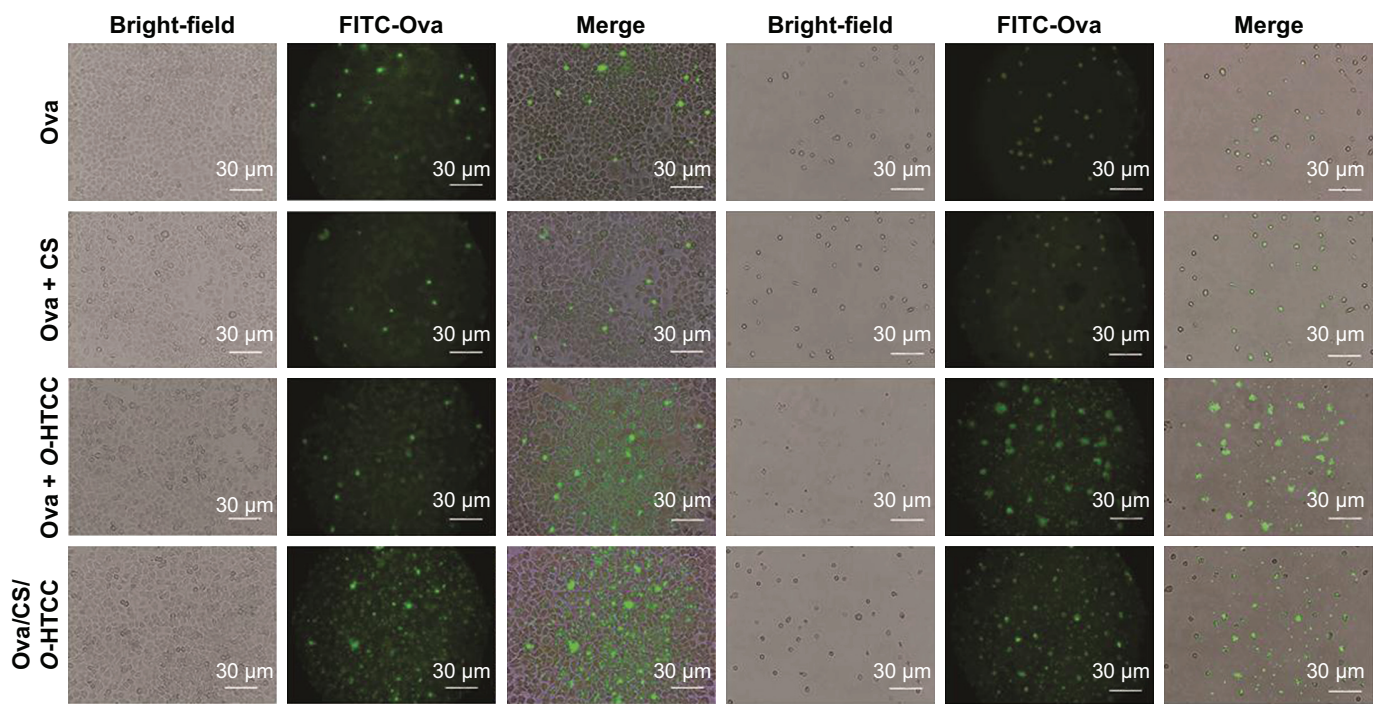

DC 2.4

Peritoneal macrophages

Figure S4 Internalization of the FITC-Ova-loaded complexes in APCs.

Note: Fluorescence microscopy analysis of FITC-Ova uptake (400x) in DC2.4 cell lines and peritoneal macrophages.

Abbreviations: FITC, fluorescein isothiocyanate; CS, curdlan sulfate; $\mathrm{O}$-HTCC, 0 -(2-hydroxyl)propyl-3-trimethyl ammonium chitosan chloride; Ova, ovalbumin.

International Journal of Nanomedicine

\section{Publish your work in this journal}

The International Journal of Nanomedicine is an international, peerreviewed journal focusing on the application of nanotechnology in diagnostics, therapeutics, and drug delivery systems throughout the biomedical field. This journal is indexed on PubMed Central, MedLine, CAS, SciSearch ${ }^{\circledR}$, Current Contents $₫ /$ Clinical Medicine,

\section{Dovepress}

Journal Citation Reports/Science Edition, EMBase, Scopus and the Elsevier Bibliographic databases. The manuscript management system is completely online and includes a very quick and fair peer-review system, which is all easy to use. Visit http://www.dovepress.com/ testimonials.php to read real quotes from published authors.

Submit your manuscript here: http://www.dovepress.com/international-journal-of-nanomedicine-journal 